Aus der Klinik für Hals-, Nasen-, Ohrenheilkunde, Kopf- und Halschirurgie (Direktorin: Prof. Dr. med. Petra Ambrosch) im Universitätsklinikum Schleswig-Holstein, Campus Kiel an der Christian-Albrechts-Universität zu Kiel

\title{
Immunhistochemische Analyse der LOXL-4 Expression und ihre klinisch-pathologische Relevanz bei Ovarialkarzinomen
}

\author{
Inauguraldissertation \\ zur \\ Erlangung der Doktorwürde der Zahnheilkunde \\ der Medizinischen Fakultät \\ der Christian-Albrechts-Universität zu Kiel \\ vorgelegt von \\ Vivian Serke \\ aus Eckernförde
}

Kiel (2018) 
1. Berichterstatter: Priv. Doz. Dr. rer. nat. Tibor Görögh

2. Berichterstatter: Prof. Dr. Birte Größner-Schreiber

Tag der mündlichen Prüfung: 19.12.2018

Zum Druck genehmigt, Kiel den 28.10.18

Prof. Dr. Johann Roider

(Vorsitzender des Ausschusses für Promotion) 
Memoria mea socri

Jürgen Kademann 


\section{Inhaltsverzeichnis}

I. Abbildungsverzeichnis........................................................................ I

II. Tabellenverzeichnis..................................................................................... II

III. Abkürzungsverzeichnis......................................................................... III

IV. Pufferlösungen und Reagenzien.............................................................. IV

1. Einleitung ..........................................................................................

1.1 Das Ovarialkarzinom................................................................................ 1

1.1.1 Epidemiologie des Ovarialkarzinoms......................................................... 1

1.1.2 Risikofaktoren................................................................................

1.1.3 Symptome und Diagnose...................................................................... 3

1.1.4 Stadieneinteilung................................................................................. 4

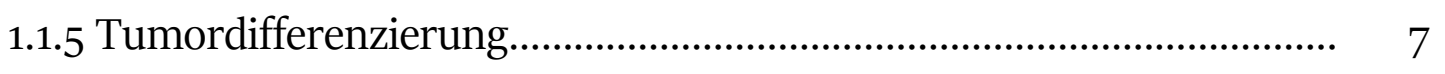

1.1.6 Therapie und Prognose.......................................................................... 8

1.1.7 Tumormarker..................................................................................... 9

1.1.8 Lysyloxidase.......................................................................................

1.2 Zielsetzung .............................................................................................. 14

2. Material und Methoden........................................................................ 15

2.1 Gewebeproben und klinisch-pathologische Daten................................... 15

2.2 Herstellung und Beschreibung der TMA-Proben...................................... 16

2.3 Primär- und Sekundärantikörper........................................................ 17

2.4 Immunhistochemische Untersuchung..................................................... 17

2.5 Mikroskopische Auswertung................................................................... 19

2.6 Statistische Auswertung.............................................................................. $\quad 19$

3. Ergebnisse ........................................................................................ 20

3.1 LOXL-4 Expression bei Primärtumoren........................................................ 20 
3.2 Korrelation zwischen LOXL-4 Expression und klinisch-

pathologischen Parametern...................................................................... 23

3.2.1 LOXL-4 und das Operationsalter........................................................... 24

3.2.2 LOXL-4 und das Tumor-Grading........................................................... $\quad 25$

3.2.3 LOXL-4 und der Fernmetastasenstatus.................................................. $\quad 27$

3.2.4 LOXL-4 und die FIGO-Klassifikation...................................................... 29

3.2.5 LOXL-4 und die Rezidivrate................................................................. 31

3.3 Zusammenhang zwischen LOXL-4 Expression und Gesamtüberleben. 32

3.3.1 Stadien der LOXL-4 Expression in Abhängigkeit vom

Gesamtüberleben..................................................................................... 34

4. Diskussion................................................................................................ 36

4.1 LOXL-4 und das Ovarialkarzinom.............................................................. 37

4.2 Diagnostische Wertigkeit der LOXL-4Expression.................................... 38

4.2.1 Operationsalter der Patientinnen.......................................................... 38

4.2.2 LOXL-4 und das Tumor-Grading.......................................................... 39

4.2.3 LOXL-4 und der Fernmetastasenstatus................................................... 40

4.2.4 LOXL-4 und die FIGO-Klassifikation..................................................... 41

4.2.5 LOXL-4 und die Rezidivrate................................................................... 42

4.3 Prognostische Wertigkeit der LOXL-4 Expression

LOXL-4-Expressionstärke und das Gesamtüberleben............................. $\quad 42$

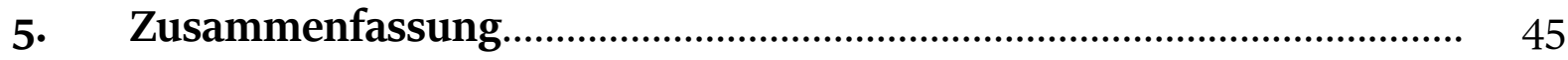

6. Literaturverzeichnis........................................................................... 46

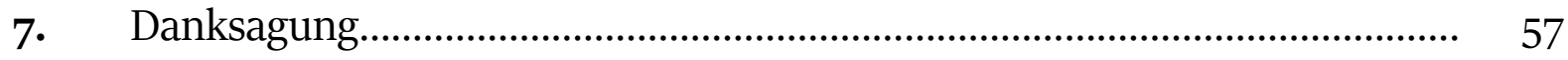

8. Veröffentlichungen........................................................................................ 58 


\section{Abbildungsverzeichnis}

Abbildung 1: Altersverteilung der Ovarialkarzinom-Patientinnen .16

Abbildung 2: Immunhistochemischer Nachweis der LOXL-4-Reaktivität. 21

Abbildung 3: Negativkontrolle aus benigner Mundschleimhaut. 22

Abbildung 4: Verteilung der untersuchten Ovarialkarzinom-Patientinnen in drei verschiedene Altersgruppen zum Operationszeitpunkt in Prozent...... 24

Abbildung 5: Verteilung der verschiedenen Tumor-Grading-Typen in Prozent........ 26

Abbildung 6: Quantitative Verteilung des Fernmetastasenstatus 27

Abbildung 7: Verteilung der untersuchten Ovarialkarzinome in $\leq 2 \mathrm{~cm}$ große Tumore und $>2 \mathrm{~cm}$ große Tumore in Prozent. 29

Abbildung 8: Verteilung der Rezidivrate in Prozent 31

Abbildung 9: Graphische Darstellung der Überlebenszeit von OvarialkarzinomPatientinnen (Kaplan-Meier-Methode) 33

Abbildung 10: Zeitverlauf von Überlebenskurven in Abhängigkeit von verschiedenen LOXL-4 Expressionsstadien mittels der Kaplan-Meier-Methode. 35 


\section{Tabellenverzeichnis}

Tabelle 1: Klassifikation des Ovarialkarzinoms

Tabelle 2: Stadieneinteilung der LOXL-4 Expression über einen semiquantitativen Maßstab.

Tabelle 3: Häufigkeit der LOXL-4 Expressionsstärke bei Primärtumoren 22

Tabelle 4: LOXL-4 Expressionsgruppen bei primären Ovarialkarzinomen. 23

Tabelle 5: LOXL-4 Expression und das Operationsalter 25

Tabelle 6: LOXL-4 Expression und das Tumor-Grading 26

Tabelle 7: LOXL-4 Expression und der Fernmetastasenstatus 28

Tabelle 8: LOXL-4 Expression und die modifizierte FIGO-Klassifikation 30

Tabelle 9: LOXL-4 Expression und die Rezidivrate ..... 32

Tabelle 1o: Überlebensraten beim Ovarialkarzinom. 33

Tabelle 11: Überlebensrate in Abhängigkeit der LOXL-4 Expression 35 


\section{Abkürzungsverzeichnis}

BRCA1/2 - Gen

CA 125

DAB

FIGO

HE4

HIF

IgG

Ki-67

LOX

LOXL-1-4

LTQ- Cofaktor

M

MLH1,2,6

HNPCC

PgR

RKI

SDS-PAA

SRCR
BReast CAncer gene 1/2

Cancer-Antigen 125

3,36-Diaminobenzidin-Dihydrochlorid

Fédération Internationale de Gynécologie

et d'Obstétrique

Humanes Epididymis Protein 4

Hypoxia-Inducible-Factor

Immunglobulin G

Proliferationsmarker (Kiel-67 Kilo-Dalton)

Lysyloxidase

Lysyloxidase like Typ 1-4

Lysyl-Tyrosyl-Quinon-Cofaktor

Molar (mol/Liter)

MutL Homolog 1,2,6 genes

Hereditäres Nicht Polypöses Kolorektalem

Karzinom

Progesteronrezeptor

Robert-Koch-Institut

Sodium Dodecylsulfat-Polyacrylamid

Gelelektrophorese

Scavenger Receptor Cysteine Rich

Domains 
Sp1

TBP

TBS

Tis

TMA

TNM

Tris

UICC

WHO
Specific Protein- 1 GC - binding protein (Transkriptionsfaktor)

TATA-binding protein

(Transkriptionsfaktor)

TRIS gepufferte Kochsalzlösung

Tumor(Carcinoma) in situ

Tissue Microarray

Tumor-Node-Metastasis

Hydroxymethylaminomethan

Union International Contre le Cancer

World Health Organisation 


\section{Pufferlösungen und Reagenzien \\ Pufferlösungen}

\begin{tabular}{|c|c|}
\hline Bezeichnung & Zusammensetzung \\
\hline TBS-Lösung & $\begin{array}{l}\text { dest. Wasser, } \mathrm{NaCl} \text {, Tris/HCl, } 1 \mathrm{~N} \mathrm{NaOH} \rightarrow \mathrm{pH} \\
7,4\end{array}$ \\
\hline Zitratpuffer & $\begin{array}{l}\text { o,o1M Zitronensäuremonohydrat, 10ml } 2 \mathrm{~N} \\
\mathrm{NaOH} \rightarrow \mathrm{pH} 6,0\end{array}$ \\
\hline $\begin{array}{l}\text { Blockierungslösung der endogenen } \\
\text { Peroxidase }\end{array}$ & $\begin{array}{l}\text { Methanol mit } 1 \% \text { einer } 37 \% \text {-igen } \mathrm{H}_{2} \mathrm{O}_{2}- \\
\text { Lösung }\end{array}$ \\
\hline $\begin{array}{l}\text { Blockierungslösung } \\
\text { Vermeidung } \\
\text { Bindungen für Primär- und } \\
\text { Sekundärantikörper }\end{array}$ & TBS mit 10\% fötalem Kälberserum \\
\hline Chromogen-Lösung & $\begin{array}{l}1 \text { DAB-Tablette in } 15 \mathrm{ml} \text { TBS-Lösung, plus } \\
2 \mathrm{o} \mu \mathrm{l} \text { einer } 37 \% \text {-igen } \mathrm{H}_{2} \mathrm{O}_{2} \text {-Lösung }\end{array}$ \\
\hline Mayer's Hämalaun-Lösung & $\begin{array}{l}\text { Mayer's Hämalaun-Lösung und dest. Wasser } \\
\text { im Verhältnis 1:2 }\end{array}$ \\
\hline $\begin{array}{l}\text { Streptavidingekoppelte, alkalische } \\
\text { Phosphatase-Lösung }\end{array}$ & $\begin{array}{l}\text { Vectastain ABC Kit, Vector Laboratories, } \\
\text { Burlingame, CA, USA }\end{array}$ \\
\hline
\end{tabular}

\section{Antikörper}

\begin{tabular}{|l|l|}
\hline Bezeichnung & Art/Eigenschaft \\
\hline Primär-Antikörper & $\begin{array}{l}\text { Monoklonaler Maus-anti-LOXL-4-Antikörper } \\
\text { (Eigenherstellung PD. Dr. rer. nat. Tibor }\end{array}$ \\
\hline
\end{tabular}




\begin{tabular}{|l|l|}
\hline Bezeichnung & Art/Eigenschaft \\
\hline Sekundär-Antikörper & Polyklonaler, biotinkonjugierter anti-Maus- \\
& IgG-Antikörper (Nr. E0354, Dako GmbH, \\
& Hamburg) \\
\hline
\end{tabular}

\section{Chemikalien}

\begin{tabular}{|l|l|}
\hline Bezeichnung & Hersteller \\
\hline Ethanol & Merck KgaA, Darmstadt \\
\hline DAB & Boehringer GmbH, Mannheim \\
\hline Destilliertes Wasser & Merck KgaA, Darmstadt \\
\hline Eukitt & Sigma Aldrich GmbH, Taufkirchen \\
\hline $\mathrm{H}_{2} \mathrm{O}_{2}$ & Th.Geyer GmbH \& Co. KG, Hamburg \\
\hline Mayer's Hämalaun & Merck KgaA, Darmstadt \\
\hline Methanol & Merck KgaA, Darmstadt \\
\hline NaCl & Merck KgaA, Darmstadt \\
\hline NaOH & Merck KgaA, Darmstadt \\
\hline Tris/HCl & Sigma Aldrich GmbH, Taufkirchen \\
\hline Xylol-Ersatz-Medium & DiaTec GmbH, Bamberg \\
\hline Zitronensäure-Monohydrat & Merck KgaA, Darmstadt \\
\hline
\end{tabular}

\section{Geräte und Software}

\begin{tabular}{|l|l|}
\hline Bezeichnung & Hersteller \\
\hline Mikrowelle & Samsung, Schwalbach/Ts \\
\hline Lichtmikroskop Axioplan & Zeiss, Jena \\
\hline AxioCam ERc5s Digitalkamera & Zeiss, Jena \\
\hline SPSS 20.0 Software & SPSS Inc. An IBM Company, Chicago, IL, USA \\
\hline
\end{tabular}




\section{Einleitung}

\subsection{Das Ovarialkarzinom}

\subsubsection{Epidemiologie des Ovarialkarzinoms}

Nach dem prozentualen Anteil der häufigsten Tumorlokalisationen aller Krebserkrankungen, zählt die Krebserkrankung der Eierstöcke (Ovarialkarzinom) in Deutschland zu der acht häufigsten Form. Es gehen von allen bösartigen Neubildungen bei Frauen 3,2\% auf das Ovar zurück. Jedoch zählt es mit 5,3\% auch zu der häufigsten Todesursache aller weiblichen Genitaltumore. Das mediane Erkrankungsalter liegt bei Frauen um das 70.Lebensjahr. Demzufolge erkrankt in Deutschland eine von 71 Frauen im Laufe ihres Lebens am Eierstockkrebs. Eingeteilt in die absteigende Häufigkeit können Ovarialkarzinome zunächst in Epithel-, Stroma- und Keimzelltumore klassifiziert werden, welche wiederum in weitere verschiedene Subformen unterteilt werden. Einige sehr seltene Formen, wie beispielsweise die Keimzelltumore, können zudem schon bei Kindern und jungen Frauen auftreten (Caspritz et al. 2017).

\subsubsection{Risikofaktoren}

Die Ätiologie des Ovarialkarzinoms ist bisher noch unklar, jedoch spielen Umweltund Ernährungsfaktoren eine Rolle. Das Lebenszeitrisiko an einem Ovarialkarzinom zu erkranken, liegt in Deutschland bei 1,4\% (Caspritz et al. 2017). Neben dem zunehmenden Lebensalter und dem Faktor Übergewicht, beeinflussen hormonelle Faktoren das Risiko an einem sporadischen Ovarialkarzinom zu erkranken, ebenso primäre Sterilität, keine oder eine erst späte Gravidität und eine fehlende Stillzeit (Landen et al. 2008). Des Weiteren zählen Hormonersatztherapien, insbesondere mit 
Östrogenpräparaten postmenopausal zu den Risikofaktoren. Die Frage, ob sowohl eine frühe Menarche als auch eine späte Menopause das Risiko ebenfalls erhöht, ist noch nicht abschließend geklärt (Caspritz et al. 2017). Die Theorie, dass durch die Ovulation mit jedem Zyklus und der folglich hohen Zellproliferationsrate auch Reparaturprozesse durchlaufen werden, die durch die erhöhte DNA - Syntheserate und dem damit einhergehenden erhöhten Mutationsrisiko auch Transformationen und somit neoplastische Veränderungen auslösen können, wird durch die genannten Risikofaktoren gestützt (Fathalla 1972). Entartete, maligne Zellen können dann Substanzen produzieren, die üblicherweise im gesunden Gewebe nicht vorkommen. Oder sie können Produkte in umgebene, benigne Zellen induzieren. Hierbei kann es sich sowohl um atypische Kohlenhydratepitope oder um tumorspezifische Enzyme oder Isoenzyme als auch um onkogene Produkte und Rezeptoren handeln (Bruhn et al. 2011). Das Risiko für eine maligne Entartung steigt demzufolge mit der zunehmenden Anzahl von Ovulationen an. Für diese Theorie spricht zudem die protektive Wirkung von Ovulationshemmern, Paritäten, Tubenligaturen sowie von Hysterektomien (Riman et al. 2002, Post et al. 2005, Caspritz et al. 2017). Eine Risikoreduktion um 6o\% lässt sich durch eine 6-jährige Einnahme von Ovulationshemmern erzielen (Modugno et al. 2004). Bei ca. $10 \%$ aller Ovarialkarzinome liegt eine genetische Ursache zugrunde (Burges and Schmalfeldt 2011). Dabei liegt die häufigste Mutation auf dem BRCA1- oder dem BRCA2-Gen vor (Antoniou et al. 2003, Chen et al. 2012, Caspritz et al. 2017). Ein weiterer wichtiger Risikofaktor für die Entstehung eines Ovarialkarzinoms ist die Genmutation von MLH1, MLH2 und MLH6 bei dem Hereditären Nicht Polypösen Kolorektalem Karzinom (HNPCC) (Steinke et al. 2013) als Manifestation des Lynch-Syndroms (Bonadona et al. 2011). Des Weiteren können Ovarialkarzinome auch in Kombination bei dem Li-Fraumeni-Syndrom auftreten (Gätje et al. 2015). 


\subsubsection{Symptome und Diagnose}

Obwohl die Erkrankungs- und Sterberate seit der Jahrtausendwende abgenommen haben und auch die Anzahl der Neuerkrankungen etwas rückläufig ist, wird das Ovarialkarzinom in den meisten Fällen immer noch in einem erst späten Stadium entdeckt und weist dementsprechend eine hohe Mortalitätsrate von 6,9\% auf (Caspritz et al. 2017). Dies liegt vor allem daran, dass die Erkrankung häufig zunächst symptomfrei verläuft oder sich klinisch unspezifisch präsentiert und daher erst spät detektiert werden kann. Bei mindestens $75 \%$ der Patientinnen wird das Ovarialkarzinom in einem bereits fortgeschrittenen FIGO-Stadium (III und IV) (Fédération Internationale de Gynécologie et d'Obstétrique) zum Zeitpunkt der Erstdiagnose festgestellt (Sehouli and Fotopoulou 2012). Typische Symptome wie diffuse abdominale Beschwerden, Veränderung der Menstruation oder des Gewichtes und die Zunahme des Bauchumfanges, treten häufig erst bei Patientinnen mit fortgeschrittenem Ovarialkarzinom auf. Ein wesentlicher Grund für die meist erst sehr späte Diagnosestellung stellt die fehlende Früherkennung des Ovarialkarzinoms mittels generellen Screening dar. Laut der S3-Leitlinie von 2016 für maligne Ovarialtumore wird ein generelles Screening mit CA 125 und Transvaginalsonographie (TSV) sogar in Risikogruppen nicht empfohlen, da keine Reduktion der Mortalität nachgewiesen werden konnte (Leitlinienprogramm 2016). Zukünftig könnte die Früherkennung eines Ovarialkarzinoms oder dessen Vorläuferstufen mittels eines Nachweises von abgeschilferten Tumorzellen durch eine Tubenlavage mit anschließendem Zervixabstrich verbessert werden (Kinde et al. 2013). Bei einem Verdacht einer ovariellen Raumforderung soll laut S3Leitlinienempfehlung eine gynäkologische Spiegel- und Tastuntersuchung durchgeführt werden. Den höchsten Stellenwert als erste apparative Maßnahme nimmt die Untersuchung mittels Transvaginalsonographie (TVS) ein (Burges and 
Schmalfeldt 2011). Jedoch führten die TVS und CA 125 Bestimmung zu keiner Mortalitätsverbesserung, weshalb sie ebenfalls nicht in der aktuellen Leitlinie zur Früherkennungsdiagnostik empfohlen werden (Leitlinienprogramm 2016). Bei einem Verdacht auf ein Rezidiv kann dieser durch einen erhöhten CA 125-Wert erhärtet werden. Laut Studienlage kommt es aber zu keiner Verbesserung der Überlebenswahrscheinlichkeit (Rustin et al. 2010). Des Weiteren können die Magnetresonanztomographie, die Computertomographie oder die PositronenEmissions-Tomographie für die weitere Diagnostik hilfreich sein. Jedoch gibt es keine apparative diagnostische Maßnahme, die ein operatives Staging ersetzt und die Operabilität verlässlich beim Ovarialkarzinom einschätzen kann (Leitlinienprogramm 2016).

\subsubsection{Stadieneinteilung}

Das Staging des Ovarialkarzinoms erfolgt anhand der pTNM-Klassifikation der UICC (Union International Contre le Cancer) beziehungsweise nach der Einteilung in die FIGO-Stadien. Das von der WHO eingeführte Klassifikationsschema nutzt als Grundlage die histogenetische Herkunft der verschiedenen Ovarialkarzinomarten. Zudem werden noch Mischformen, bösartige Neoplasien, die von Lipid- und Bindegewebszellen ausgehen, sekundäre metastatische Prozesse und unklassifizierte Tumore erfasst. Für das Ovarialkarzinom gibt es seit 01.01.2014 eine Neufassung der FIGO-Stadieneinteilung (WHO Classifiaction of Tumors of Female Reproductive Organs, 2014). Die Änderungen der Neufassung sind in der folgenden Tabelle dick gedruckt hervorgehoben. Beide Klassifikationen richten sich in ihrem Staging sowohl nach den klinisch-präoperativen, intraoperativ makroskopischen als auch nach den histopathologischen und zytologischen Befunden. 
Tabelle 1: Klassifikation des Ovarialkarzinoms

\begin{tabular}{|c|c|c|}
\hline $\begin{array}{c}\text { TNM- } \\
\text { Kategorien }\end{array}$ & $\begin{array}{l}\text { FIGO- } \\
\text { Stadien }\end{array}$ & Definitionen \\
\hline $\mathrm{Tx}$ & & Primärtumor kann nicht beurteilt werden \\
\hline $\mathrm{T}_{0}$ & & kein Anhalt für Primärtumor \\
\hline $\mathrm{T}_{1}$ & $\mathrm{I}$ & Tumor begrenzt auf Ovarien \\
\hline $\mathrm{T}_{1} \mathrm{a}$ & IA & $\begin{array}{l}\text { Tumor auf ein Ovar begrenzt; Kapsel intakt; kein Tumor } \\
\text { auf der Oberfläche des Ovars, keine malignen Zellen in } \\
\text { Aszites oder bei Peritoneallavage }\end{array}$ \\
\hline $\mathrm{T}_{1} \mathrm{~b}$ & IB & $\begin{array}{c}\text { Tumor auf beide Ovarien begrenzt; Kapsel intakt; kein } \\
\text { Tumor auf der Oberfläche des Ovars, keine malignen Zellen } \\
\text { in Aszites oder bei Peritoneallavage }\end{array}$ \\
\hline $\mathrm{T}_{1} \mathrm{C}$ & $\begin{array}{c}\text { IC } \\
\mathbf{1} \\
\mathbf{2}\end{array}$ & $\begin{array}{l}\text { Tumor begrenzt auf ein oder beide Ovarien; } \\
\text { Iatrogene Kapselruptur } \\
\text { Präoperative Kapselruptur oder Tumore auf der } \\
\text { Ovarialoberfläche } \\
\text { maligne Zellen im Aszites oder in der Spülzytologie }\end{array}$ \\
\hline $\mathrm{T}_{2}$ & II & $\begin{array}{l}\text { Tumor befällt ein Ovar oder beide Ovarien und breitet sich } \\
\qquad \text { im Becken aus }\end{array}$ \\
\hline $\mathrm{T}_{2} \mathrm{a}$ & IIa & $\begin{array}{c}\text { Ausbreitung auf und/oder Implantate an Uterus und/oder } \\
\text { Tube(n); keine malignen Zellen in Aszites oder bei } \\
\text { Peritoneallavage }\end{array}$ \\
\hline
\end{tabular}




\begin{tabular}{|c|c|c|}
\hline $\mathrm{T}_{2} \mathrm{~b}$ & $\mathrm{IIb}$ & $\begin{array}{c}\text { Ausbreitung auf andere Beckengewebe; keine malignen } \\
\text { Zellen in Aszites oder bei Peritoneallavage }\end{array}$ \\
\hline $\mathrm{T} 2 \mathrm{C}$ & IIc & $\begin{array}{l}\text { Ausbreitung im Becken (2a oder 2b) und maligne Zellen in } \\
\text { Aszites oder bei Peritoneallavage; } \\
\text { entfällt nach der aktuellen FIGO-Klassifizierung }\end{array}$ \\
\hline T3 u/o N1 & III & $\begin{array}{l}\text { Tumor befällt ein Ovar oder beide Ovarien mit } \\
\text { mikroskopisch nachgewiesenen Peritonealmetastasen } \\
\text { außerhalb des Beckens und/oder regionären } \\
\text { Lymphknotenmetastasen }\end{array}$ \\
\hline \multirow[t]{5}{*}{ Тза } & IIIA & $\begin{array}{l}\text { retroperitoneale Lymphknotenmetastasen und/oder } \\
\text { mikroskopische Metastasen außerhalb des Beckens }\end{array}$ \\
\hline & $\mathbf{1}$ & $\begin{array}{c}\text { ausschließlich retroperitoneale } \\
\text { Lymphknotenmetastasen }\end{array}$ \\
\hline & & i Metastasen max. $10 \mathrm{~mm}$ \\
\hline & 2 & ii Metastasen größer als $10 \mathrm{~mm}$ \\
\hline & & $\begin{array}{l}\text { mikroskopische Peritonealmetastasen jenseits des } \\
\text { Beckens mit oder ohne retroperitoneale } \\
\text { Lymphknotenmetastasen }\end{array}$ \\
\hline $\mathrm{T}_{3} \mathrm{~b}$ & IIIB & $\begin{array}{l}\text { makroskopische Peritonealmetastasen jenseits des } \\
\text { Beckens; größte Ausdehnung } 2 \text { cm oder weniger mit } \\
\text { oder ohne retoperitoneale Lymphknotenmetastasen; } \\
\text { schließt Ausbreitung auf Leberkapsel und Milz mit ein }\end{array}$ \\
\hline
\end{tabular}




\begin{tabular}{|c|c|c|}
\hline T3c u/o N1 & IIIC & $\begin{array}{c}\text { Peritonealmetastasen jenseits des Beckens; größte } \\
\text { Ausdehnung mehr als } 2 \text { cm, und/oder retroperitoneale } \\
\text { Lymphknotenmetastasen; schließt eine Ausbreitung } \\
\text { auf Leberkapsel und Milz mit ein }\end{array}$ \\
\hline \multirow[t]{3}{*}{ M1 } & IV & Fernmetastasen (ausschließlich Peritonealmetastasen) \\
\hline & IVA & Pleuraerguss mit positiver Zytologie \\
\hline & IVB & $\begin{array}{c}\text { parenchymale Metastasen der Leber und/oder der } \\
\text { Milz; Metastasen zu außerhalb des Abdomens } \\
\text { gelegenen Organe (einschließlich inguinaler } \\
\text { Lymphknotenmetastasen und/oder anderer außerhalb } \\
\text { des Abdomens gelegener Lymphknotenmetastasen) }\end{array}$ \\
\hline
\end{tabular}

\subsubsection{Tumordifferenzierung}

Gut definierte Kriterien für das histopathologische Grading von Ovarialkarzinomen sind erstmals durch Shimizu et al., 1998 vorgeschlagen worden. Dabei wurden durch die Autoren neben der Kernpleomorphie auch die Mitosezahl und der Differenzierungsgrad der Architektur der Zellen bestimmt.

Das histopathologische Grading wird unterteilt in:

G1 = gut differenziert, G2 = mäßig differenziert und G3 = gering differenziert. 


\subsubsection{Therapie und Prognose}

Das therapeutische Vorgehen erfolgt in erster Linie durch eine radikale chirurgische Sanierung mit dem Ziel der Entfernung des gesamten sichtbaren Tumorgewebes. Hierbei werden standardmäßig eine Hysterektomie mit Adnektomie und zusätzlicher Appendektomie und eine Omentektomie empfohlen (Feige et al. 2005). Da die Befunde durch die späte Detektion meist sehr ausgeprägt sind und eine Ro-Resektion nicht möglich ist, stellt die darauf folgende Kombinations-Chemotherapie die zweite wichtige Therapiesäule dar. Hierbei stellen Cis bzw. Carboplatin in Verbindung mit einem Taxan den Therapiestandard dar und haben zu einer weiteren Verbesserung der Prognose bei einem fortgeschrittenen Tumorstadium beigetragen. Die Verabreichung erfolgt über 6 Zyklen. Durch diese Vorgehensweise lässt sich eine 5Jahres-Überlebensrate von circa 50\% stadienübergreifend erreichen (Feige et al. 2005). Den wichtigsten prognostischen Faktor stellt das Tumorstadium und somit die Ausbreitung des Tumors bei der Erstdiagnose dar. Zudem zeigten Frühstadien (FIGO I und II) deutlich bessere 5-Jahres-Überlebens-Prognosen, als fortgeschrittene Ovarialkarzinom Stadien (FIGO III und IV). Laut einer Studie von Brun und Mitarbeiter sinkt die 5-Jahres-Überlebensrate mit zunehmendem Stadium und damit beträgt die 5-Jahres-Überlebensrate ca. 76\% im FIGO-Stadium I, 42\% im Stadium II, 21\% im Stadium III und letztendlich nur noch 6\% im Stadium IV (Brun et al. 2000). Der Verlauf der Erkrankung bei einem höhergradigen Befall ist zudem durch die Größe der verbleibenden Tumorreste und das Ansprechen auf die verabreichte Polychemotherapie gekennzeichnet. Die Therapieempfehlung für Patientinnen aus einer Risikogruppe stellt die prophylaktische Salpingo-Oophorektomie dar. Diese Therapiemöglichkeit wird durch diverse Studien untermauert (Rebbeck et al. 2002). Der Gruppe der Hochrisikopatientinnen sollte sowohl eine multidisziplinäre Beratung, als auch eine genetische Ermittlung des Ovarialkarzinoms für eine genaue 
Abklärung angeboten werden. Zu den gängigen Prognosefaktoren zählen neben dem Tumorstadium, das Alter, der Allgemeinzustand, das Tumor-Grading, der histologische Typ, die leitliniengerechte Therapie und vor allem der postoperative Tumorrest (Leitlinienprogramm 2016). Eine Rezidivrate von $65 \%$ der fortgeschrittenen Ovarialkarzinome trotz maximaler operativer und medikamentöser Therapie verdeutlicht die eigentliche Problematik der Therapie des Eierstockkrebses.

Diese hohe Rezidivrate ist zudem verantwortlich für die geringe 5-JahresÜberlebensrate von unter $30 \%$ bei einem fortgeschrittenen Ovarialkarzinom (Bookman 2005). Häufig ist ein chemoresistentes Rezidiv mit einer ausgedehnten Peritonealkarzinose der Grund, weshalb nur noch die Palliativtherapie angewendet werden kann. Dieses ernüchternde Fazit verdeutlicht die Wichtigkeit der Entwicklung neuer Therapiestrategien für die Behandlung des Ovarialkarzinoms.

\subsubsection{Tumormarker}

Die Suche nach gezielten Laborparametern, die ein malignes Wachstum zuverlässig detektieren können, um ein mögliches pathogenes Wachstum frühzeitig sichtbar zu machen und effektiv behandeln zu können, beschäftigt Forscher schon seit dem neunzehnten Jahrhundert. Den Grundstein für die Antigen-Antikörper-Reaktion und dem damit verbundenen Prinzip der rezeptorgesteuerten Immunreaktion formulierte Paul Ehrlich mittels seiner Seitenkettentheorie bereits vor mehr als 100 Jahren. Doch erst die Entwicklung der benötigten Hybridtechnologie ermöglichte die Produktion labortechnisch hergestellter monoklonaler Antikörper (mAk). Diese Technologie wurde von Köhler und Milenstein 1975 entwickelt und trieb die Forschung um die monoklonalen Antikörper entschieden voran. Durch den vielseitigen medizinischen Nutzen in der Diagnostik und der Therapie wird auch bei 
der Erkrankung an einem Ovarialkarzinom versucht, einen möglichst zuverlässigen Antikörper zu finden, welcher bestenfalls sowohl in der Früherkennungsdiagnostik als auch für die molekularbiologisch zielgerichtete Therapiestrategie eingesetzt werden könnte. Zu den aktuellen Tumormarkern des Ovarialkarzinoms zählt das CA 125. Seine prognostische Wertigkeit zum Zeitpunkt der Diagnose, zudem vor der neo-adjuvanten Behandlung und auch nach den Zyklen von adjuvanten Chemotherapien, konnte mittels verschiedener Studien belegt werden (Kim et al. 2008, Kang 2011, Chen et al. 2013, Moon et al. 2013). Ein weiterer Tumormarker ist das epididymale Protein 4 (HE4). Dieses zählt zu der Familie der ProteaseInhibitoren und wird überwiegend von Zellen des serösen und endometroiden Ovarialkarzinoms sezerniert. Jedoch ist $\mathrm{HE}_{4}$ kein spezifischer Tumormarker für das Ovarialkarzinom, da ebenso bei einem Adenokarzinom des Endometriums und auch bei einem Nierenversagen erhöhte Werte auftreten (Lenhard et al. 2011, Molina et al. 2011). HE4 wird lediglich eine bessere Sensitivität, vor allem in frühen Krankheitsstadien, bei einer Spezifität von 95\% bestätigt (Sarojini et al. 2012). Die Sensitivität lässt sich durch die Kombination von $\mathrm{HE}_{4}$ mit CA-125 auf 76\% steigern, wobei die Spezifität gleichbleibend hoch ist. Die Suche und Entwicklung nach weiteren neuen Tumormarkern rückt immer mehr in den wissenschaftlichen Fokus, um die dringend notwendigen Fortschritte im Bereich der Diagnostik, der prognostischen Aussagefähigkeit sowie der therapeutischen Behandlungsmöglichkeit des Ovarialkarzinoms erzielen zu können und ist daher von großer klinischer Relevanz. 


\subsubsection{Lysyloxidase}

Ein Tumormarker, der in letzter Zeit immer mehr Aufmerksamkeit bei Studien zur Erforschung von Krebsgeschehen erhält, ist die Lysyloxidase (LOX) (Deng et al. 2014, Diercks and Görögh 2015, Li et al. 2015). Zum jetzigen Zeitpunkt wird die Wirkung des LOX-Subtypes LOXL-4 in Ovarialkarzinomzellen noch kontrovers diskutiert. Um die Zusammenhänge der in dieser Arbeit untersuchten LOXL-4 Expressionen und der verschiedenen Besonderheiten des LOXL-4 Enzyms besser verstehen zu können, werden im folgenden dessen Grundlagen dargestellt.

Das für das LOXL-4 Protein kodierte Gen liegt auf dem Chromosom 10q24 (Asuncion et al. 2001). Zudem enthält der $4 \mathrm{~kb}$ lange kodierende Genbereich 14 Exone (Asuncion et al. 2001, Maki et al. 2001). LOXL-4 gehört zu den kupferabhängigen AminOxidasen, die mit den anderen LOX Isoformen (LOXL, LOXL2, LOXL3) eine Enzymfamilie bilden. Charakteristisch für die Isoformen ist, dass sie eine fast identische N-terminale Region aufweisen (Wang et al. 1996, Maki et al. 2001, Molnar et al. 2003). Gekennzeichnet wird diese N-terminale Domäne durch vier Scavenger Receptor Cystein Rich Domains (SRCRs), welche sich nur minimal in ihrem Aufbau und ihrer Funktion voneinander unterscheiden (Asuncion et al. 2001). Sie wurden bereits in vielfältigen Zusammenhang mit unterschiedlichen karzinomatösen Erkrankungen analysiert (Csiszar 2001, Kirschmann et al. 2002, Holtmeier et al. 2003). Der konservierte Lysyl- und Tyrosyl-Rest sorgt bei der Entstehung des LTQCofaktors (Lysyl-Tyrosyl-Quinon-Cofaktor) für die katalytische Aktivität von LOX. Durch diese katalytische Aktivität wird die Quervernetzung zwischen Laminin und Kollagen bewirkt, wodurch ihnen eine bedeutende Rolle bei dem Aufbau und der Aufrechterhaltung der Extrazellularmatrix (ECM) zukommt. Zudem stehen sie in Interaktion bei der Zelladhäsion (Molnar et al. 2003), der Zellwachstumskontrolle (Csiszar 2001), der zellulären Seneszenz, der Tumorgenese (Saito et al. 1997, Csiszar 
2001, Wiel et al. 2013) und bei der Chemotaxis (Lucero et al. 2008, Lucero et al. 2011). Des Weiteren diskutieren andere Autoren die Funktion des LOX-Gens und dessen Familienmitgliedern als Tumorsuppressorgene. Das LOX-Gen und dessen Subtypen fungieren somit als Antatgonisten zum Ras-Onkogen (Min et al. 2007, Wu et al. 2007). Ihre homologen C-Terminalen Domänen dienen als KupferBindungsstellen. LOXL-4 ist seit 2001 ein immer häufigerer Bestandteil in wissenschaftlichen Arbeiten. Durch die Untersuchungen mit Promotor-ReportergenKonstrukten konnte dargelegt werden, dass an der Regulation der LOXL-4 Genexpression die Transkriptionsfaktoren TBP und Sp1 mitwirken (Görögh et al. 2008). Bei Untersuchungen an Karzinomen des oberen Aerodigestivtraktes konnten Holtmeyer und Mitarbeiter eine verstärkte Expression des LOXL-4 Gens beschreiben (Holtmeier et al. 2003). Anhand von vergleichenden Genexpressionsanalysen legten die Autoren dar, dass im Vergleich zu gesunden pharyngealen Epithelzellen die LOXL-4-mRNA in Plattenepithelkarzinomzellen aus Kopf-Halstumoren eine starke Expression aufweisen. Darüber hinaus konnten Görögh und Mitarbeiter eine signifikante Korrelation zwischen der LOXL-4 Genexpression und der Lymphknotenmetastasierung herausfinden, sowie eine erhöhte Anzahl des LOXL-4 Genlocus auf Chromosom 10q24 (Gorogh et al. 2007). Des Weiteren können vergleichend die Ergebnisse der LOXL-4 Überexpression des Mammakarzinoms herangezogen werden, welches neben dem Ovarialkarzinom eine der Hauptursachen für die Letalität durch gynäkologische Malignomen darstellt (Bundesamt 2015). Kirschmann und Mitarbeiter konnten die Überexpression des LOXL-4 Gens aus invasiven Mamma Karzinomzellen feststellen (Kirschmann et al. 2002). Die These, dass LOX beim invasiven Verhalten der Zellen maßgeblich beteiligt ist, ließ sich zusätzlich beweisen, da durch die Gabe des LOX-Inhibitors Beta-Aminopropionitril das invasive Potential der Zellen abnahm (Kirschmann et al. 2002). In Bezug auf das 
Ovarialkarzinom konnten Roffeis und Mitarbeiter die mehr als 20 fache Erhöhung der Expression der 15-LOX-2 im maligne entarteten Gewebe (Primärtumor und Metastasen) bei Ovarialkarzinomen beweisen (Roffeis 2011). De Donato und Mitarbeiter beschrieben die Auswirkungen von erhöhten LOX-Expressionswerten auf die Tumorprogression und das Metastasierungsverhalten bei serösen Ovarialkarzinomen (De Donato et al. 2017). Bislang liegt jedoch keine statistisch repräsentative Untersuchung über die Expression des LOX-Subtyps LOXL-4 auf Proteinniveau beim Ovarialkarzinom vor. 


\subsection{Zielsetzung}

Ziel der vorliegenden Untersuchung ist es, die Expression von LOXL-4 in 104 histopathologisch gesicherten in Formalin fixierten und in Paraffin eingebetteten Tissue Microarray (TMA) Gewebeschnitten immunhistochemisch zu analysieren. Vor dem Hintergrund dieser Untersuchung sollen folgende Analysenschritte chronologisch ausgeführt werden:

1. Zuerst soll die Spezifität des monoklonalen Maus-Antikörpers gegen das LOXL-4 Protein in Ovarialkarzinom-Biopsaten gezeigt werden. In simultanen Versuchen sollen gesunde Mundschleimhaut-Biopsate bei gleicher Antikörperkonzentration untersucht werden.

2. Die immunhistochemischen Färbungen sollen nach definierten Auswertungskriterien in Gruppen eingeteilt werden, die negative, schwache, moderate und starke Färbung repräsentieren.

3. Um Antworten auf die Fragen zu finden, ob sich zwischen der LOXL-4 Expression und dem retrospektiv ausgewerteten Patientengut eine Beziehung ergibt, soll die Höhe der LOXL-4 Expression unter Berücksichtigung verschiedener klinisch-histopathologischer Parameter wie der FIGOKlassifizierung, dem Alter und der Überlebenszeit bei Biopsatentnahme ausgewertet werden.

4. Schließlich soll die Frage diskutiert werden, inwiefern das immunhistochemische Reaktionsmuster von LOXL-4 bei den diagnostischen Kriterien des Ovarialkarzinoms berücksichtigt werden kann. 


\section{Material und Methoden}

\subsection{Gewebeproben und klinisch-pathologische Daten}

Diese Arbeit bediente sich der Methode der histologisch gesicherten und gestanzten, in Formalin fixierten und in Paraffin eingebetteten Tissue Microarray (TMA)Gewebeschnitte. Mit diesem Verfahren wurden insgesamt 104 Ovarialkarzinome in Vierfachbestimmung und somit 416 Gewebeproben umfassend untersucht, dokumentiert und ausgewertet. Demgegenüber dienten als Negativproben zehn benigne Mundschleimhautproben, die im Rahmen von operativen Eingriffen an gesunden Probanden aus dem weichen Gaumen entnommen wurden. Als Grundlage für die weitere Analyse und Auswertung wurden die dazugehörigen klinischpathologischen Befunde in einer Patientendatenbank dokumentiert. Durch diese Erhebung konnte die Krankheitsgeschichte der jeweiligen Patientin mit unterschiedlichen Parametern ermittelt und zusammengestellt werden.

In der Datenbank wurden die folgenden klinisch-histopathologischen Parameter erhoben:

- Operationsalter

- Fernmetastasen-Status

- Tumor-Grading

- FIGO - Klassifizierung

- Rezidivrate

- Gesamtüberleben

Bei der Erstdiagnose lag das Patientinnenalter zwischen 26 und 88 Jahren. Das mediane Alter zu dem Operationszeitpunkt betrug 61,69 Jahre. Die quantitative Altersverteilung zum Zeitpunkt der Operation ist in Abbildung 1 dargestellt. 


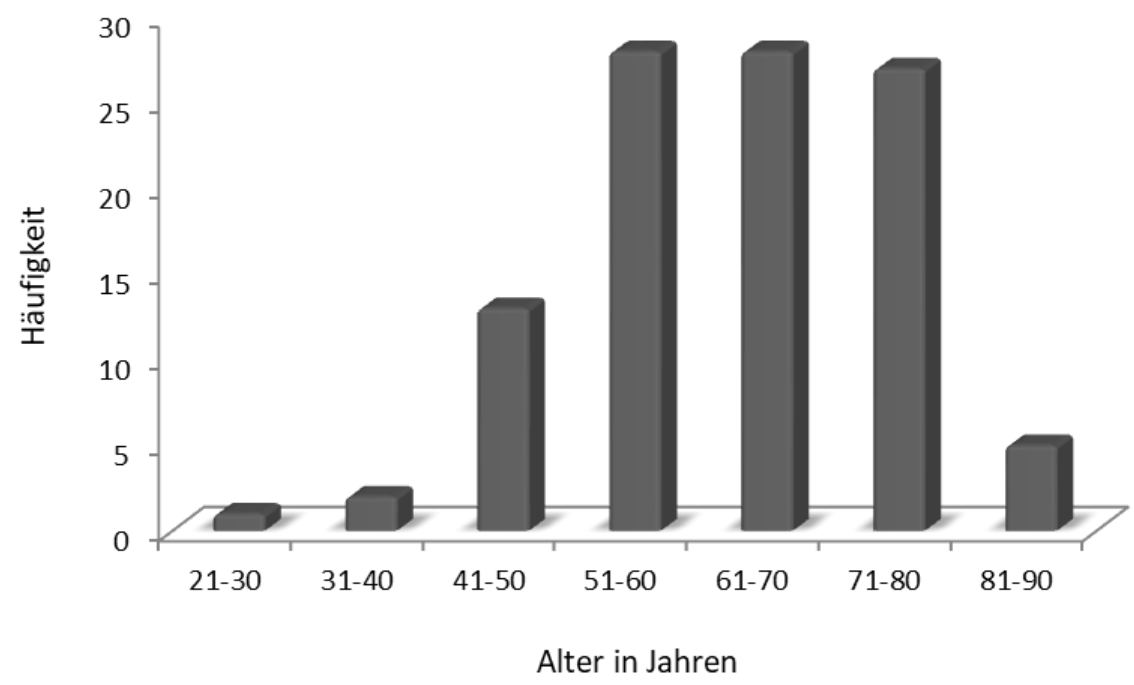

Abbildung 1: Altersverteilung der Ovarialkarzinom-Patientinnen bei

Operationsdatum

Von allen Patientinnen wurde gemäß des befürworteten Ethikantrages durch die

Ethikkommission des Universitätsklinikums Kiel eine schriftliche Einverständniserklärung zur wissenschaftlichen Bearbeitung des Gewebes, dem Helsinki Abkommen entsprechend (AZ-Nr.: B327/10), vorab eingeholt.

\subsection{Herstellung und Beschreibung der TMA-Proben}

Im Zeitraum vom 29.08.1998 bis zum 17.10.2011 wurden die TMA-Proben von dem Universitätsklinikum für Frauenheilkunde der Christian-Albrechts-Universität zu Kiel fertiggestellt und die erhobenen klinisch-histopathologischen Daten in einer speziellen Datenbank erfasst. Auf einem Objektträger befanden sich vier Stanzen eines resezierten Ovarialkarzinoms. Der Durchmesser der Stanzen betrug 2,5mm. Die Stanzen wurden in einem Abstand von 1,1mm auf den Objektträger aufgetragen. 


\subsection{Primär- und Sekundär-Antikörper}

Im Rahmen dieser Arbeit wurde das LOXL-4 Protein in Ovarialkarzinom-Biopsaten mit einem primären monoklonalen Maus-anti-LOXL-4-Antikörper (Eigenherstellung PD. Dr. T. Görögh, HNO-Klinik Kiel) und einem anschließenden sekundären polyklonalen biotin-konjugierten anti-Maus-IgG-Antikörper (Dako, Hamburg) mittels immunhistochemischer Analyse nachgewiesen. Anhand der SDSGelelektrophorese und dem Western-Blot wurden die Spezifität und Sensitivität des LOXL-4-Antikörpers überprüft. Zudem konnte eine Kreuzreaktion mit anderen Proteinspezies ausgeschlossen werden (Gorogh et al. 2007, Weise et al. 2008).

\subsection{Immunhistochemische Untersuchung}

Die zu untersuchenden TMA-Proben wurden für zweimal zehn Minuten in einem Xylol-Ersatz-Medium als Vorbehandlung entparaffiniert. Die anschließende Dehydrierung der Biopsate erfolgte in einer absteigenden Alkoholreihe (zweimal für zehn Minuten in 100\% Ethanol, einmal für fünf Minuten in 95\% Ethanol, einmal für fünf Minuten in $80 \%$ Ethanol und einmal für fünf Minuten in $70 \%$ Ethanol). Nach dem Spülvorgang mit destilliertem Wasser erfolgte die zehnminütige Inkubation der Präparate in einer TBS-Lösung. Die Mikrowellen-Methode nach Brown und Chirala fand zu der Demaskierung der Proben Verwendung (Brown and Chirala 1995). Die auf dem Objektträger fixierten TMA-Proben wurden in eine mikrowellengeeignete Plastikküvette überführt und mittels Zitratpuffer bedeckt. Die Präparate wurden bei 800 Watt für vierzehn Minuten erhitzt. Dabei durfte es nicht zum Aufkochen der Präparate kommen. Anschließend erfolgte die Abkühlung der Proben auf Zimmertemperatur und der erneute Spülvorgang mit destilliertem Wasser. Zur Inhibierung der endogenen Peroxidase-Aktivität wurden die Proben für zehn Minuten in einer Blockinglösung, bestehend aus Methanol mit o,37\% $\mathrm{H}_{2} \mathrm{O}_{2}$, 
inkubiert. Danach wurden die Schnitte in destilliertes Wasser gelegt und anschließend mit TBS gespült. Im nächsten Schritt wurden die Präparate mit einer Lösung, bestehend aus fötalem Kälberserum (FCS) und phosphatgepufferter Salzlösung (PBS) (6o $\mu 1$ FCS in 2ml PBS), für fünf Minuten überschichtet, um unspezifische Bindungsstellen $\mathrm{zu}$ blockieren. Die hier modifiziert angewendete Immunperoxidase-Methode beruht auf der Immunperoxidase-Methode nach Hsu und Mitarbeitern (Hsu et al. 1981). Das Verfahren startete mit der Inkubation der Proben für sechzig Minuten mit dem primären monoklonalen Maus-anti-LOXL-4Antikörper $(1 \mu \mathrm{g} / \mathrm{ml})$ bei einer 1:30o Verdünnung. Daraufhin folgte ein Spülvorgang der Proben in TBS-Lösung für dreimal fünf Minuten. Anschließend wurde der Sekundärantikörper, ein polyklonaler, biotinylierter anti-Maus-IgG-Antikörper bei einer Verdünnung von 1:300, auf die Biopsate appliziert und diese wurden für weitere dreißig Minuten inkubiert. Darauffolgend wurden die ungebundenen Komplexbestände für weitere dreimal zwei Minuten mit einer TBS-Lösung abgespült. Um den Immunkomplex zu visualisieren, erfolgte eine zwanzig minütige Inkubation mit einer 30o $\mu$ l Chromogen-Lösung unter Verwendung von DAB (3,36Diaminobenzidin-Dihydrochlorid). Die an die Chromogen-Färbung anschließende Inkubation in einer TBS-Lösung erfolgte für zehn Minuten. Um die Färbung zu stoppen, wurden die Proben mit destilliertem Wasser abermals gespült. Die Mayer'sche Hämalaun-Lösung zur Gegenfärbung der Präparate in einem Verhältnis von 1:2 wurde für eine Einwirkzeit von dreißig Sekunden angewandt. Eine Wässerung der Präparate erfolgte für zehn Minuten unter fließendem Leitungswasser. Zum Schluss wurden die Präparate durch eine aufsteigende Alkoholreihe dehydriert, zweimal zehn Minuten in einem Xylol-Ersatzmedium inkubiert, anschließend mit Eukitt überschichtet und letztendlich zur Vorbereitung auf das Mikroskopieren, mit einem Deckglas abgedeckt. 


\subsection{Mikroskopische Auswertung}

Das Lichtmikroskop (Axioplan, Zeiss, Göttingen) wurde für die Betrachtung und Auswertung der gefärbten TMA-Proben verwendet. Mittels der integrierten Mikroskop-Digitalkamera AxioCam ERc5s wurde die Fotodokumentation erhoben. Zwei unabhängige Untersucher, die zum Zeitpunkt der Auswertung keine klinischpathologischen Befunde kannten, begutachteten die Präparate und werteten die mikroskopischen Ergebnisse aus.

\subsection{Statistische Analyse}

Für die Datenerfassung und die statistische Analyse wurde die Software SPSS 20.0 verwendet. Somit konnten die in der Datenbank festgehaltenen Ergebnisse verschiedener Vorläuferstudien mit in die Analyse einfließen. Die Codierung der LOXL-4 Expressionsraten erfolgte als nominal skaliertes Merkmal mit den klinischhistopathologischen Daten. Dies ermöglichte eine Abbildung in absoluten und prozentualen Häufigkeiten. LOXL-4 wurde mit einem der genannte Parametern in Kontingenztafeln gegenübergestellt und anschließend mit dem Chi-Quadrat-Test nach Pearson und dem Likelihood-Quotienten auf seine diagnostische Wertigkeit überprüft. Durch diese Vorgehensweise ließ sich ein Nachweis über eine signifikante Abhängigkeit zwischen den einzelnen Daten erstellen. Der p-Wert kleiner $\leq$ 0,05 wurde als statistisch signifikant, $\quad \mathrm{p} \leq 0,01$ als hoch signifikant und $\mathrm{p} \leq 0,001$ als statistisch höchst signifikant gewertet. 


\section{Ergebnisse}

\subsection{LOXL-4 Expression bei Primärtumoren}

Im Mittelpunkt der immunhistochemischen Untersuchung standen 104 primäre Ovarialkarzinome und deren mögliche LOXL-4 Reaktivität. 2 Biopsate konnten aufgrund von Beschädigungen nicht ausgewertet werden. Nach der Datenerfassung erfolgte die lichtmikroskopische Auswertung mittels einer Stadieneinteilung. Dafür wurde die LOXL-4 Expression über einen semiquantitativen Maßstab in vier Stadien mit negativer, schwacher, moderater und starker LOXL-4 Expressionsstärke eingeteilt (Tabelle 2).

Tabelle 2: $\quad$ Stadieneinteilung der LOXL-4 Expression über einen semiquantitativen Maßstab

\begin{tabular}{|cc|}
\hline Negativ & $<1 \%$ \\
\hline Schwach & $<10 \%$ \\
\hline Moderat & $<25 \%$ \\
\hline Stark & $>25 \%$ \\
\hline
\end{tabular}

Die lichtmikroskopische Darstellung von LOXL-4 mit seiner unterschiedlichen Expressionsstärke und der daraus resultierenden Stadieneinteilung werden in Abbildung 2 veranschaulicht. 

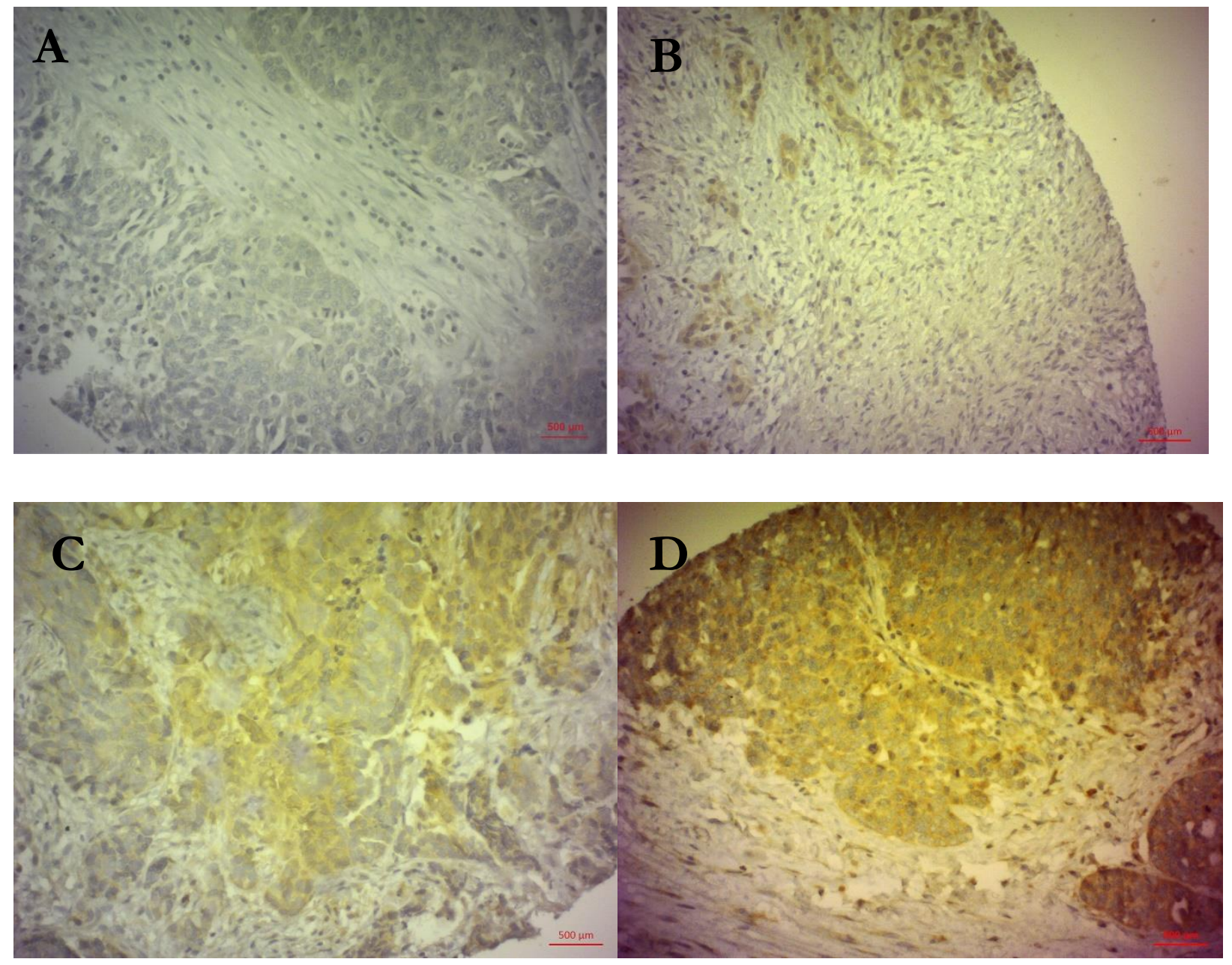

Abbildung 2: Immunhistochemischer Nachweis der LOXL-4 Reaktivität.

Zu sehen sind Ovarialkarzinom-Biopsate mit (A) negativer, (B)

schwacher, (C) moderate und (D) starker LOXL-4 Expression

Zum Spezifitätsnachweis des LOXL-4-Antikörpers wurden benigne Mundschleimhaut-Biopsate als Kontrollgruppe verwendet. Dieses benigne Gewebe weist im Vergleich zu den Ovarialkarzinom-Biopsaten keine LOXL-4 Färbung auf (Abbildung 3). 


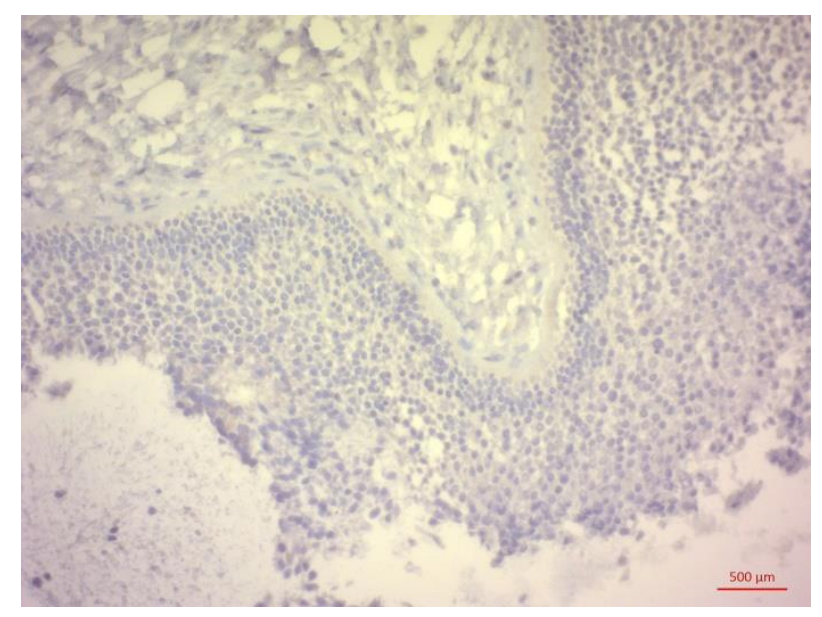

Abbildung 3: Negativkontrolle aus benigner Mundschleimhaut.

Im Gewebe ist keine Antikörperreaktivität gegen LOXL-4 zu erkennen.

Tabelle 3 veranschaulicht die Anzahl der immunhistochemisch gefärbten Primärtumore in der beschriebenen Gruppeneinteilung. Bei der Untersuchung der Häufigkeiten der LOXL-4 Expression konnte eines (1\%) der 102 Ovarialkarzinome mit einer schwachen LOXL-4 Expression erfasst werden. 61 (61\%) Primärtumore wiesen eine moderate und 40 (39\%) Primärtumore eine starke LOXL-4 Expression auf.

Tabelle 3: Häufigkeit der LOXL-4 Expressionsstärke bei Primärtumoren

\begin{tabular}{|c|c|c|}
\hline LOXL-4 Expression & Häufigkeit [n] & Prozent [\%] \\
\hline Schwach & 1 & $1 \%$ \\
\hline Moderat & 61 & $60 \%$ \\
\hline Stark & 40 & $39 \%$ \\
\hline Gesamt [n] & 102 & $100 \%$ \\
\hline
\end{tabular}


Um eine genauere Aussage über das Ovarialkarzinom zu treffen, wurde eine spezifische Kategorisierung in die Gruppen mit schwach-moderater und starker LOXL-4 Expression verwendet. Tabelle 4 veranschaulicht dieses Einteilungsschema. Bei der Auswertung konnten 62 (61\%) der Primärtumore als schwach-moderat bewertet werden. Die restlichen 40 (39\%) Biopsate wiesen eine starke LOXL-4 Expression auf.

Tabelle 4: LOXL-4 Expressionsgruppen bei primären Ovarialkarzinomen

\begin{tabular}{|c|c|c|}
\hline LOXL-4 Expression & Häufigkeit [n] & Prozent \\
\hline Schwach-Moderat & 62 & $61 \%$ \\
\hline Stark & 40 & $39 \%$ \\
\hline Gesamt [n] & 102 & $100 \%$ \\
\hline
\end{tabular}

\subsection{Korrelation zwischen LOXL-4 Expression und klinisch-pathologischen Parametern}

\subsubsection{LOXL-4 und das Operationsalter}

Zu den Prognoseparametern des Ovarialkarzinoms zählen neben dem Stadium, dem postoperativ verbleibenden Tumorrest und dem Allgemeinzustand der Patientinnen, auch das jeweilige Alter. Aus diesem Grund wurde das Alter zum Operationszeitpunkt in Korrelation mit der LOXL-4 Expression untersucht. Für eine genauere statistische Auswertung wurde die Patientinnenkohorte nach ihrem Alter in drei Gruppen eingeteilt. 
In Abbildung 4 wird das Alter der Patientinnen zum Operationszeitpunkt und deren prozentuale Verteilung in den drei Gruppen ( $\leq 50$ Jahre, 51-70 Jahre und $\geq 71$ Jahre) dargestellt. Die kleinste Gruppe umfasste mit 15\% die Patientinnengruppe in einem Alter von $\leq 50$ Jahren. Die Patientinnengruppe mit einem Operationsalter von $\geq 71$ Jahre war mit 30\% vertreten. Den größten Anteil mit 55\% der Patientinnen machte die Gruppe der 51-70 Jährigen aus.

\section{Operationsalter}

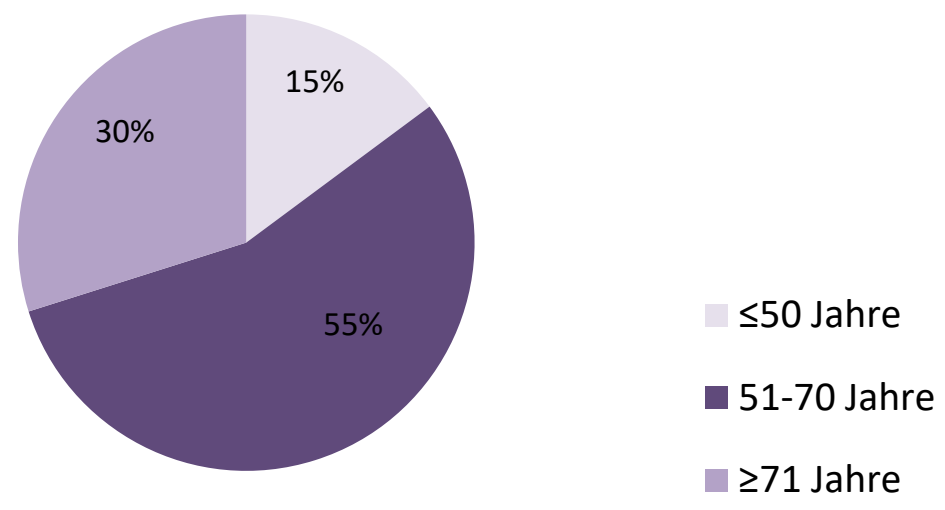

Abbildung 4: Verteilung der untersuchten Ovarialkarzinom-Patientinnen in drei verschiedene Altersgruppen zum Operationszeitpunkt in Prozent [\%].

In Tabelle 5 ist die prozentuale und nummerische Verteilung der untersuchten Altersgruppen in Korrelation mit der LOXL-4 Expression dargestellt. Eine statistische Beziehung zwischen den Altersgruppen und der LOXL-4 Expression konnte mit dem exakten Test nach Fischer nicht ermittelt werden $(p=0,502)$. 
Tabelle 5: LOXL-4 Expression und das Operationsalter

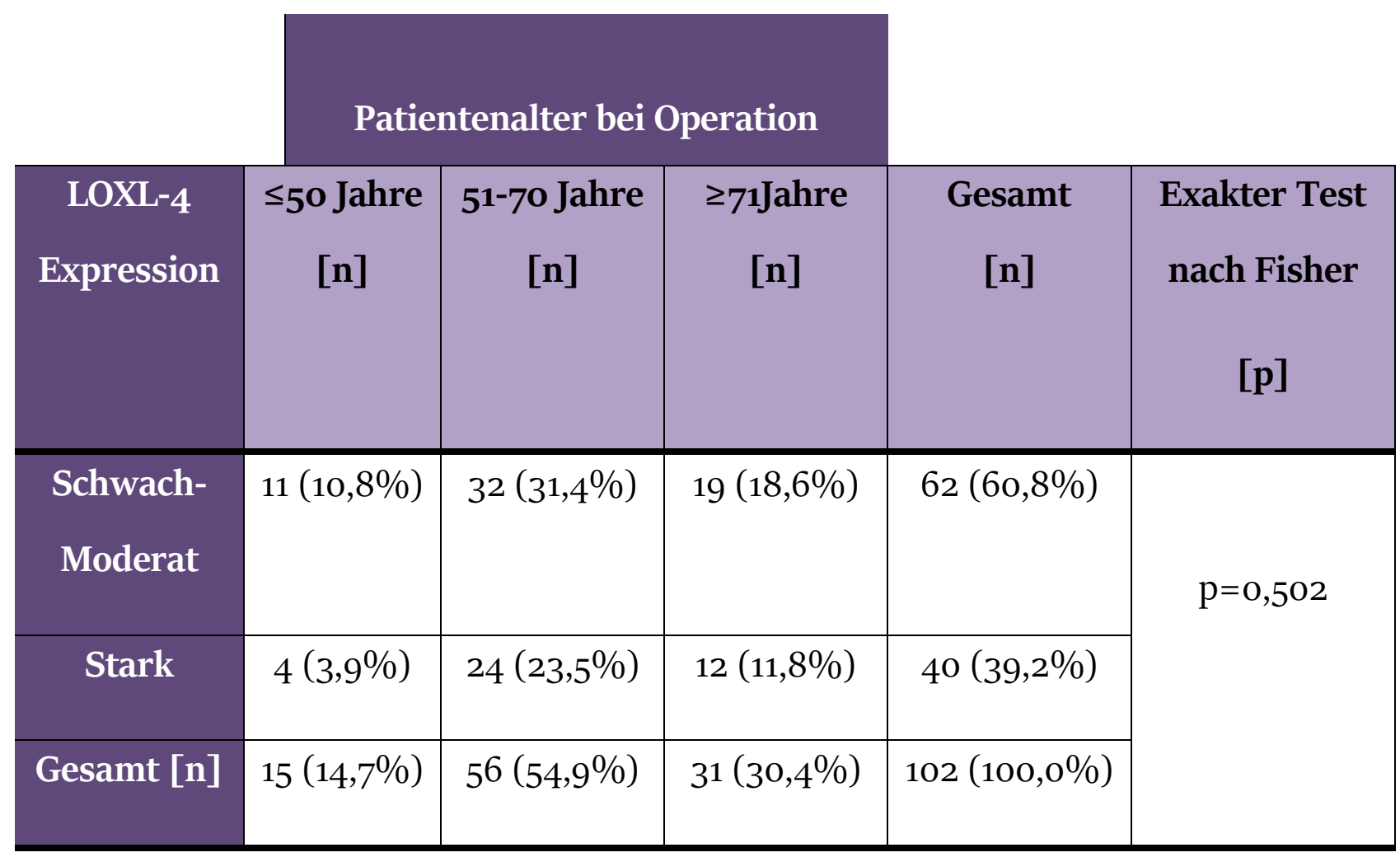

\subsubsection{LOXL-4 und das Tumor-Grading}

Damit Patientinnen eine verlässliche und dem Tumor zugehörige Therapie erfahren können, lag ein weiteres Augenmerk dieser statistischen Untersuchung auf dem Tumor-Grading. Bei der Datengewinnung konnten drei (2,9\%) gut differenzierte G1Tumore, 46 (45,1\%) mäßig differenzierte G2-Tumore und $53(52,0 \%)$ schlecht differenzierte G3-Tumore erfasst werden (Abbildung 5). 


\section{Tumor - Grading}

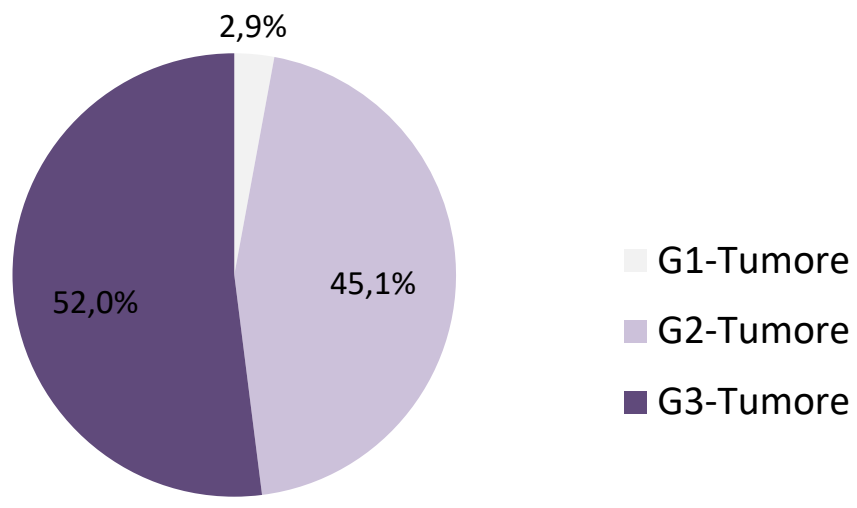

Abbildung 5: Verteilung der verschiedenen Tumor-Grading-Typen in Prozent [\%]

Tabelle 6 veranschaulicht die Verteilung der unterschiedlichen Tumor-GradingTypen in Korrelation mit ihrer spezifischen LOXL-4 Expressionsstärke. Es konnte beim Exakten Test nach Fisher ein signifikanter Zusammenhang zwischen dem Tumor-Grading und der LOXL-4 Expression ermittelt werden $(p=0,018)$.

Tabelle 6: LOXL-4 Expression und das Tumor-Grading

\begin{tabular}{|c|c|c|c|c|c|}
\hline $\begin{array}{c}\text { LOXL-4 } \\
\text { Expression }\end{array}$ & G1 [n] & G2 [n] & $\mathrm{G}_{3}[\mathrm{n}]$ & $\begin{array}{c}\text { Gesamt } \\
{[\mathrm{n}]}\end{array}$ & $\begin{array}{c}\text { Exakter Test } \\
\text { nach Fisher }[p]\end{array}$ \\
\hline $\begin{array}{l}\text { Schwach- } \\
\text { Moderat }\end{array}$ & $\begin{array}{c}3 \\
(2,9 \%)\end{array}$ & $\begin{array}{c}33 \\
(32,4 \%)\end{array}$ & $\begin{array}{c}26 \\
(25,5 \%)\end{array}$ & $\begin{array}{c}62 \\
(60,8 \%)\end{array}$ & \\
\hline Stark & $\begin{array}{c}0 \\
(0 \%)\end{array}$ & $\begin{array}{c}13 \\
(12,7 \%)\end{array}$ & $\begin{array}{c}27 \\
(26,5 \%)\end{array}$ & $\begin{array}{c}40 \\
(39,2 \%)\end{array}$ & $p=0,018$ \\
\hline Gesamt [n] & $\begin{array}{c}3 \\
(2,9 \%)\end{array}$ & $\begin{array}{c}46 \\
(45,1 \%)\end{array}$ & $\begin{array}{c}53 \\
(52,0 \%)\end{array}$ & $\begin{array}{c}102 \\
(100 \%)\end{array}$ & \\
\hline
\end{tabular}




\subsubsection{LOXL-4 und der Fernmetastasenstatus}

Ein weiterer wichtiger diagnostischer Faktor des Ovarialkarzinoms stellt der Fernmetastasenstatus dar. Dieser ist kongruent $\mathrm{zu}$ dem FIGO-IV-Stadium und beschreibt Fernmetastasen im Bereich des Peritoneums. Folgend wird der Fernmetastasenstatus gesondert statistisch untersucht.

In Abbildung 6 ist die prozentuale Verteilung der untersuchten Ovarialkarzinomkohorte nach dem Vorhandensein von Fernmetastasen im Peritoneum veranschaulicht. Dabei konnte diagnostisch bei 15\% der Patientinnen, die an einem Ovarialkarzinom erkrankten, Fernmetastasen ermittelt werden. Bei 85\% wurden keine Fernmetastasen im Peritoneum diagnostiziert.

\section{Fernmetastasenstatus}

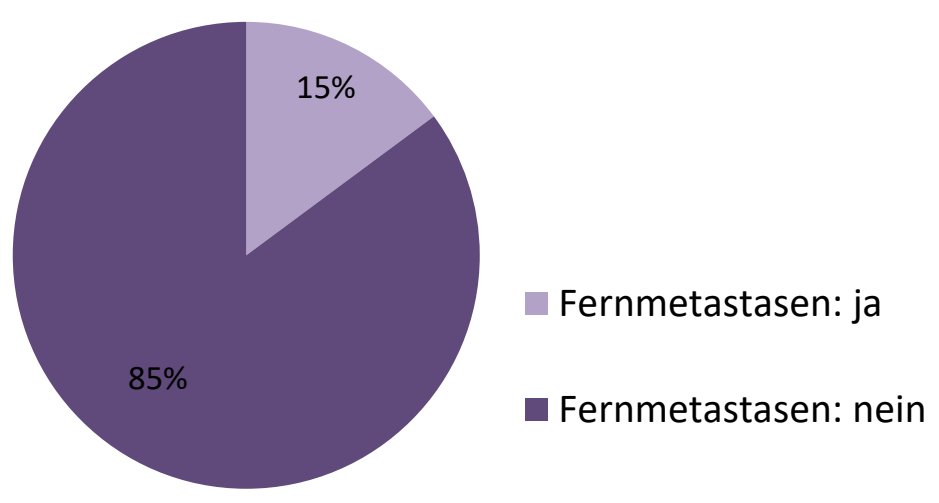

Abbildung 6: Quantitative Verteilung des Fernmetastasenstatus bei Ovarialkarzinomen in Prozent [\%] 
In Tabelle 7 sind die nummerischen und prozentualen Verteilungswerte der LOXL-4 Expression in Korrelation mit dem Fernmetastasenstatus aufgeführt. Dabei konnten von den 102 bekannten LOXL-4-reaktiven Ovarialkarzinomen 101 Karzinome auf ihren Fernmetastasenstatus untersucht werden. Von den 14,9\% positiven Fernmetastasen wiesen 9,9\% eine schwach-moderate und 5,0\% eine starke LOXL-4 Expression auf. Von den 86 Tumoren mit einem negativen Fernmetastasenstatus wiesen 50,5\% eine schwach-moderate und 34,6\% eine starke LOXL-4 Expression auf. Durch die Berechnung mit dem Exakten Test nach Fischer konnte keine statistische Signifikanz zwischen der LOXL-4 Expression und dem Fernmetastasenstatus ermittelt werden $(p=0,776)$.

Tabelle 7: $\quad$ LOXL-4 Expression und der Fernmetastasenstatus

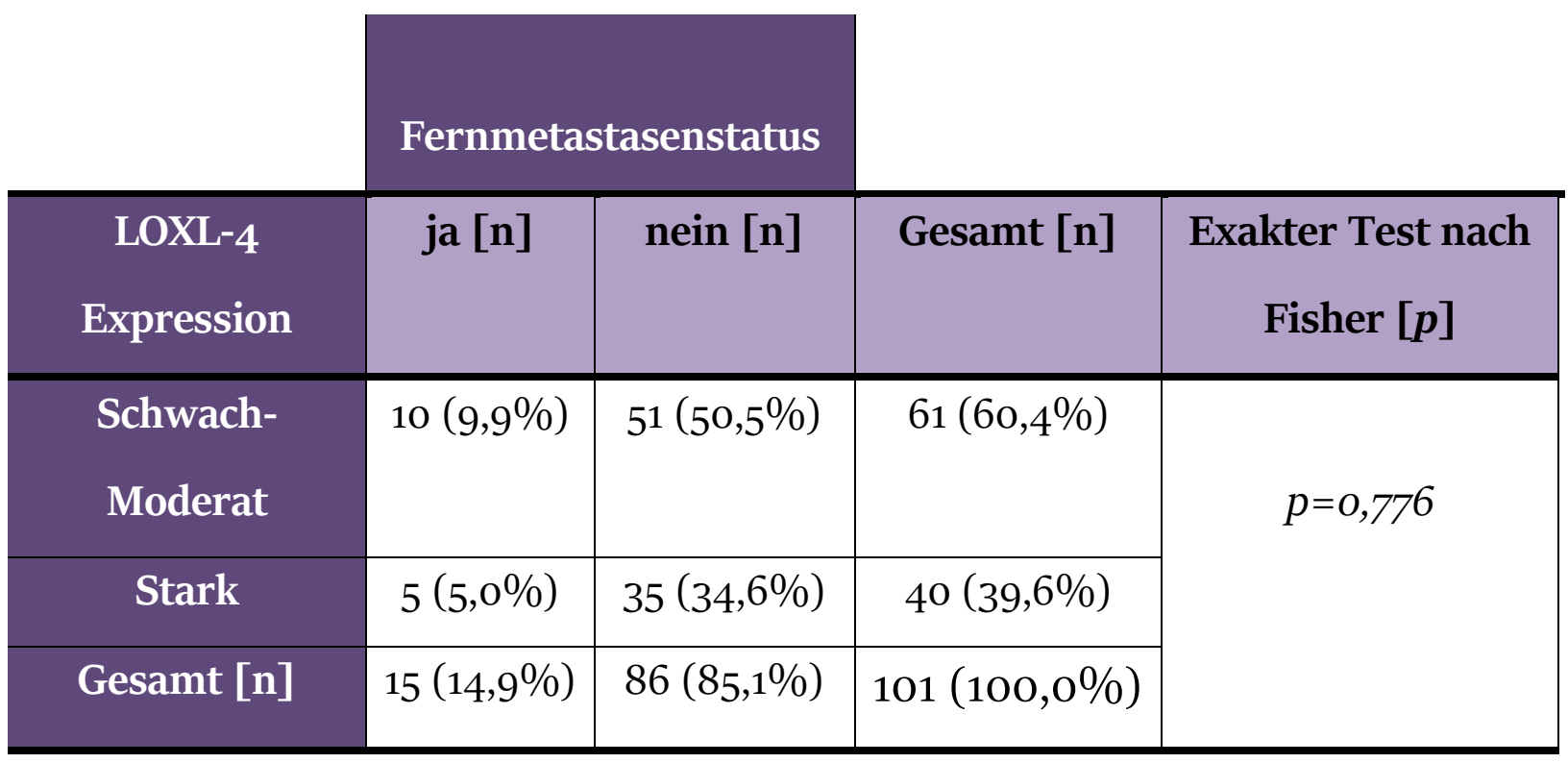




\subsubsection{LOXL-4 und die FIGO-Klassifikation}

Ein weiterer Schwerpunkt der vorliegenden Arbeit besteht darin, festzustellen, ob zwischen der LOXL-4 Expression und der FIGO-Klassifikation bei OvarialkarzinomPatientinnen eine Korrelation besteht. Hierbei wurde, um die Fallzahl zu erhöhen, die FIGO-Klassifikation in die Gruppe der $\leq 2 \mathrm{~cm}$ großen Tumore ( $1 \mathrm{a}-3 \mathrm{~b})$ und in die Gruppe der $>$ 2 cm großen Tumore (3c) zusammengefasst. Zudem wurde in der statistischen Auswertung der FIGO-Klassifikation das FIGO-Stadium IV nicht mit einbezogen, da es sich um Fernmetastasen im Bereich des Peritoneums handelte, welche zusätzlich gesondert statistisch untersucht wurden.

Wie in Abbildung 7 dargestellt, wurden bei Diagnosestellung in $65,1 \%$ der Fälle Tumore mit einer Ausdehnung von $>2 \mathrm{~cm}$ ermittelt. In 34,9\% der Fälle wies der Tumor eine Ausdehnung von $\leq 2 \mathrm{~cm}$ auf.

\section{FIGO-Klassifikation}
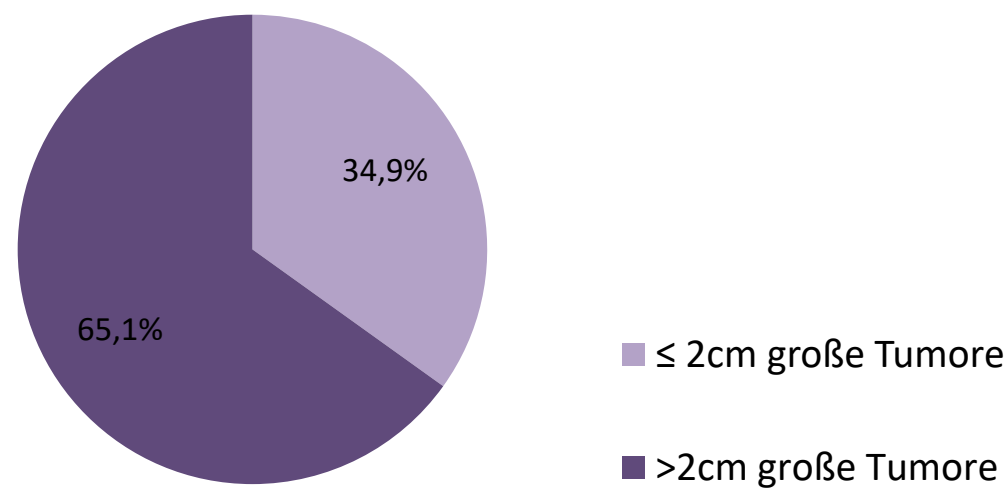

Abbildung 7: Verteilung der untersuchten Ovarialkarzinome in $\leq 2 \mathrm{~cm}$ große Tumore und $>2 \mathrm{~cm}$ große Tumore in Prozent [\%] 
Insgesamt konnten 83 Ovarialkarzinome mit histopathologisch gesicherter FIGOKlassifikation mittels statistischer Analyse untersucht werden. Die nummerische und prozentuale Verteilung der einzelnen Ovarialkarzinome ist in Tabelle 8 aufgezeigt. Durch die Berechnung mit dem Exakten Test nach Fischer konnte eine statistische Signifikanz zwischen der modifizierten FIGO-Klassifikation und der LOXL-4 Expression ermittelt werden $(\mathrm{p}=\mathrm{o}, \mathrm{o11})$.

Tabelle 8: $\quad$ LOXL-4 Expression und die modifizierte FIGO-Klassifikation in $\leq 2 \mathrm{~cm}$ großer Tumor und >2cm große Tumore

\begin{tabular}{|c|c|c|c|c|}
\hline \multicolumn{5}{|c|}{ FIGO-Klassifikation } \\
\hline $\begin{array}{c}\text { LOXL-4 } \\
\text { Expression }\end{array}$ & $\begin{array}{l}\leq 2 \mathrm{~cm} \text { große } \\
\text { Tumore [n] }\end{array}$ & $\begin{array}{l}>2 \mathrm{~cm} \text { große } \\
\text { Tumore [n] }\end{array}$ & Gesamt [n] & $\begin{array}{c}\text { Exakter } \\
\text { Test nach } \\
\text { Fisher }[p]\end{array}$ \\
\hline $\begin{array}{l}\text { Schwach- } \\
\text { Moderat }\end{array}$ & $23(27,7 \%)$ & $27(32,5 \%)$ & $50(60,2 \%)$ & $p=0,011$ \\
\hline Stark & $6(7,2 \%)$ & $27(32,5 \%)$ & $33(39,8 \%)$ & \\
\hline Gesamt [n] & $29(34,9 \%)$ & $54(65,1 \%)$ & $83(100,0 \%)$ & \\
\hline
\end{tabular}




\subsubsection{LOXL-4 und die Rezidivrate}

Das Ovarialkarzinom hat eine bekanntlich hohe Rezidivrate und folglich eine schlechtere Prognose für die betroffenen Patientinnen. Daher liegt ein wichtiger Fokus dieser Arbeit infolgedessen auch auf der Rezidivrate der untersuchten Ovarialkarzinomkohorte. Wie in Abbildung 8 verdeutlicht, entwickelten 69,6\% der Ovarialkarzinom-Patientinnen ein Rezidiv.

\section{Rezidivrate}

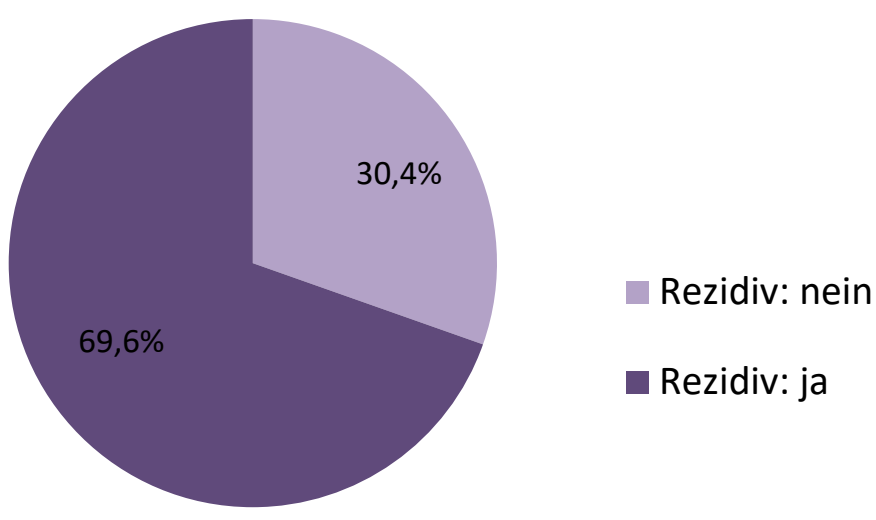

Abbildung 8: Verteilung der Rezidivrate in Prozent [\%]

Zum Zeitpunkt der Datenerfassung konnte bei 71 Patientinnen eine rezidivierende Erkrankung festgestellt werden. Bei 31 Patientinnen entwickelte sich kein Rezidiv und galten somit als rezidivfrei (Tabelle 9). Eine statistische Korrelation zwischen der Rezidivrate und der LOXL-4 Expression konnte anhand des Exakten Tests nach Fisher nicht ermittelt werden $(p=0,508)$. 
Tabelle 9: LOXL-4 Expression und die Rezidivrate

\begin{tabular}{|c|c|c|c|c|}
\cline { 2 - 4 } & \multicolumn{2}{|c|}{ Rezidivrate } & \\
\hline $\begin{array}{c}\text { LOXL-4 } \\
\text { Expression }\end{array}$ & nein [n] & ja [n] & Gesamt [n] & $\begin{array}{c}\text { Exakter Test } \\
\text { nach Fisher [p] }\end{array}$ \\
\hline $\begin{array}{c}\text { Schwach- } \\
\text { Moderat }\end{array}$ & $17(16,7 \%)$ & $45(44,1 \%)$ & $62(60,8 \%)$ & \multirow{2}{*}{$p=0,508$} \\
\hline $\begin{array}{c}\text { Stark } \\
\text { Gesamt [n] }\end{array}$ & $31(30,4 \%)$ & $71(69,6 \%)$ & $102(100,0 \%)$ & \\
\hline
\end{tabular}

\subsection{Zusammenhang zwischen LOXL-4 Expression und Gesamtüberleben}

Als ein weiteres wichtiges Kriterium wurde das LOXL-4 Vorkommen im Hinblick auf die Gesamtüberlebensrate der an einem Ovarialkarzinom erkrankten Patientinnen betrachtet und eingehend analysiert. Von einer Patientin konnte die Überlebenszeit aufgrund von fehlenden Follow up Daten nicht ermittelt werden. Die aufgetretenen Todesfälle, die 3-Jahres-Überlebenrate, die 5-Jahres-Überlebensrate, die 10-JahresÜberlebensrate sowie die mittlere Überlebenszeit der untersuchten Patientinnen sind in Tabelle 10 dokumentiert. Der mittlere Beobachtungszeitraum betrug 3,92 Jahre. 
Tabelle 10: Überlebensraten beim Ovarialkarzinom

\begin{tabular}{|c|c|c|c|c|c|}
\hline & $\begin{array}{c}\text { Todes- } \\
\text { fälle [n] }\end{array}$ & $\begin{array}{c}\text { 3-Jahres- } \\
\text { Überlebens- } \\
\text { rate [\%] }\end{array}$ & $\begin{array}{c}\text { 5-Jahres- } \\
\text { Überlebens } \\
\text {-rate [\%] }\end{array}$ & $\begin{array}{c}\text { 10-Jahres- } \\
\text { Überlebens } \\
\text {-rate [\%] }\end{array}$ & $\begin{array}{c}\text { Mittlere } \\
\text { Überlebens- } \\
\text { zeit [Jahre] }\end{array}$ \\
\hline $\begin{array}{c}\text { Ovarial- } \\
\text { karzinom }\end{array}$ & $\begin{array}{c}77 \text { von } \\
101\end{array}$ & 55,6 & 34,1 & 18,2 & 4,0 \\
\hline
\end{tabular}

In Abbildung 9 wurde der Verlauf der Überlebenszeit mittels der Kaplan-MeierMethode veranschaulicht dargestellt. Aus dieser Graphik ist zu entnehmen, dass zum Beobachtungsende nach 13 Jahren die Überlebenswahrscheinlichkeit der an Ovarialkarzinom erkrankten Patientinnen bei $~ 15 \%$ lag.

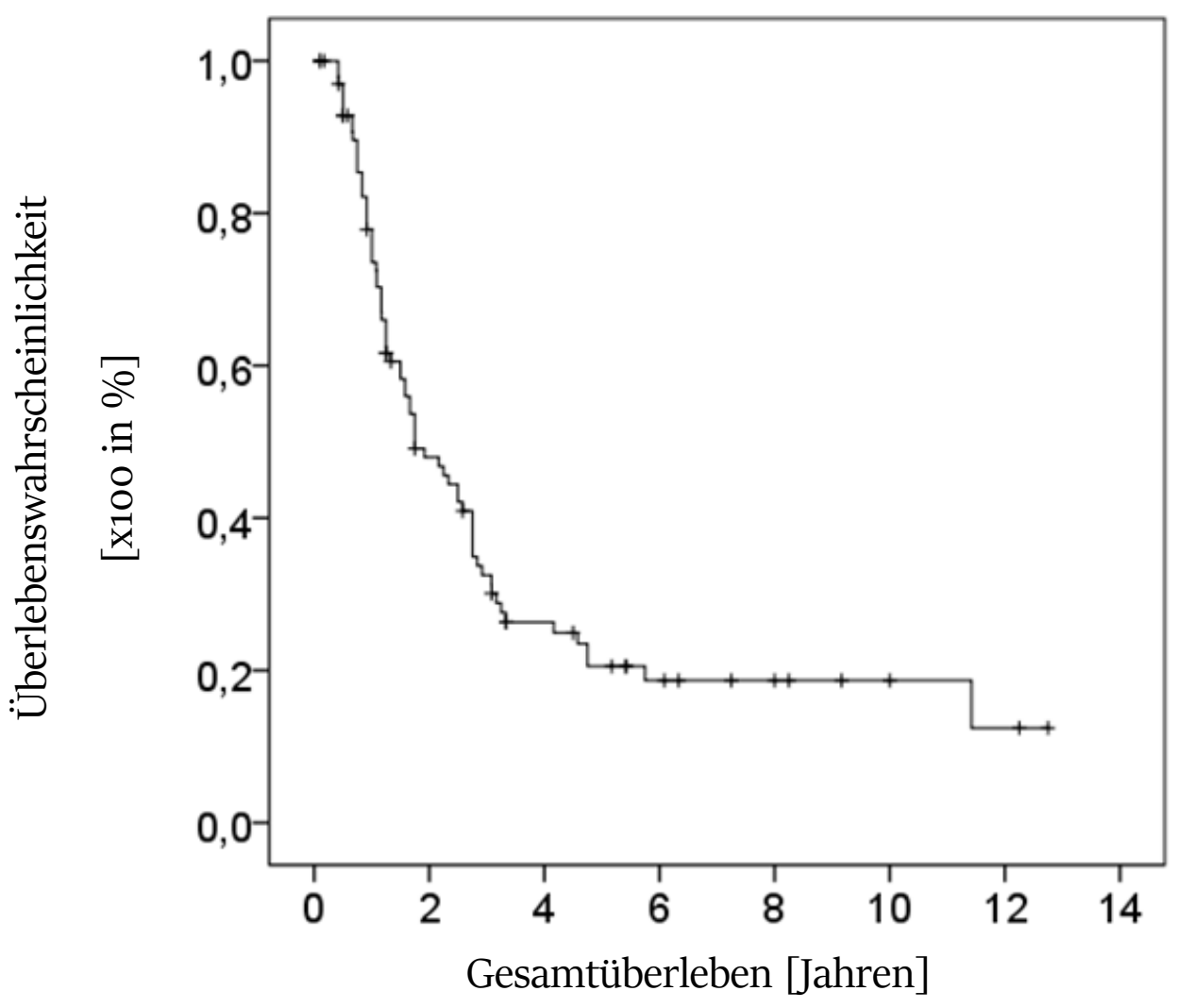

Abbildung 9: Graphische Darstellung der Überlebenszeit von OvarialkarzinomPatientinnen (Kaplan-Meier-Methode) 
Um eine prognostische Einschätzung für das Gesamtüberleben der an einem Ovarialkarzinom erkrankten Patientinnen treffen zu können, bedarf es verschiedener diagnostischer Parameter. Hierzu zählen bei dem Ovarialkarzinom neben dem Alter der Patientin bei Erstdiagnose, die FIGO-Klassifizierung und der Entartungsgrad des Tumorgewebes (Tumor-Grading). Da weder ein generelles Screening, noch ein Screening mittels CA 125 und TSV bisher zu einer Reduktion der Mortalität führte, kann ein Screening laut S3-Leitlinie nicht empfohlen werden. In der vorliegenden

Studie wurde die diagnostische und prognostische Wertigkeit von LOXL-4 bei Ovarialkarzinompatientinnen statistisch analysiert und auf das Gesamtüberleben untersucht, um den Stellenwert von LOXL-4 als Tumormarker, sowohl bei der Diagnostik als auch bei der Prognose von Ovarialkarzinom-Patientinnen zu untersuchen.

\subsubsection{Stadien der LOXL-4 Expression in Abhängigkeit vom Gesamtüberleben}

Wie in Tabelle 11 dargestellt, ließ sich zwischen der LOXL-4 Expressionsstärke und dem Gesamtüberleben keine statistische Signifikanz $(p=0,723)$ feststellen. Da sich bei der immunhisochemischen Färbung der Schnitte lediglich eine Probe schwach angefärbt hat, wurde diese zu der Gruppe der moderaten Färbungen hinzugefügt. Somit ergab es eine Gruppe mit schwach-moderater Färbung und eine mit starker LOXL-4 Färbung. 
Tabelle 11: Überlebensrate in Abhängigkeit der LOXL-4 Expression

\begin{tabular}{|c|c|c|c|c|c|}
\hline $\begin{array}{c}\text { Stadien der } \\
\text { LOXL-4 }\end{array}$ & $\begin{array}{c}\text { Todes- } \\
\text { fälle } \\
\text { Expression }\end{array}$ & $\begin{array}{c}\text { 3-Jahres- } \\
\text { Überlebens- } \\
\text { rate [\%] }\end{array}$ & $\begin{array}{c}\text { 5-Jahres- } \\
\text { Überlebens- } \\
\text { rate [\%] }\end{array}$ & $\begin{array}{c}\text { 10-Jahres- } \\
\text { Überlebens- } \\
\text { rate [\%] }\end{array}$ & $\begin{array}{c}\text { Log- } \\
\text { Rank- } \\
\text { Test }(p)\end{array}$ \\
\hline $\begin{array}{c}\text { Schwach- } \\
\text { Moderat }\end{array}$ & $45 / 61$ & $55,9 \%$ & $32,5 \%$ & $21,1 \%$ & \\
Stark & $32 / 40$ & $56,0 \%$ & $37,3 \%$ & $7,3 \%$ & 0,246 \\
\hline
\end{tabular}

Bei der Betrachtung der LOXL-4Expressionsstärke und der Überlebenswahrscheinlichkeit von Ovarialkarzinom-Patientinnen (Abbildung 10) ließ sich anhand des Log-Rank-Tests kein signifikanter Zusammenhang feststellen $(p=0,246)$.

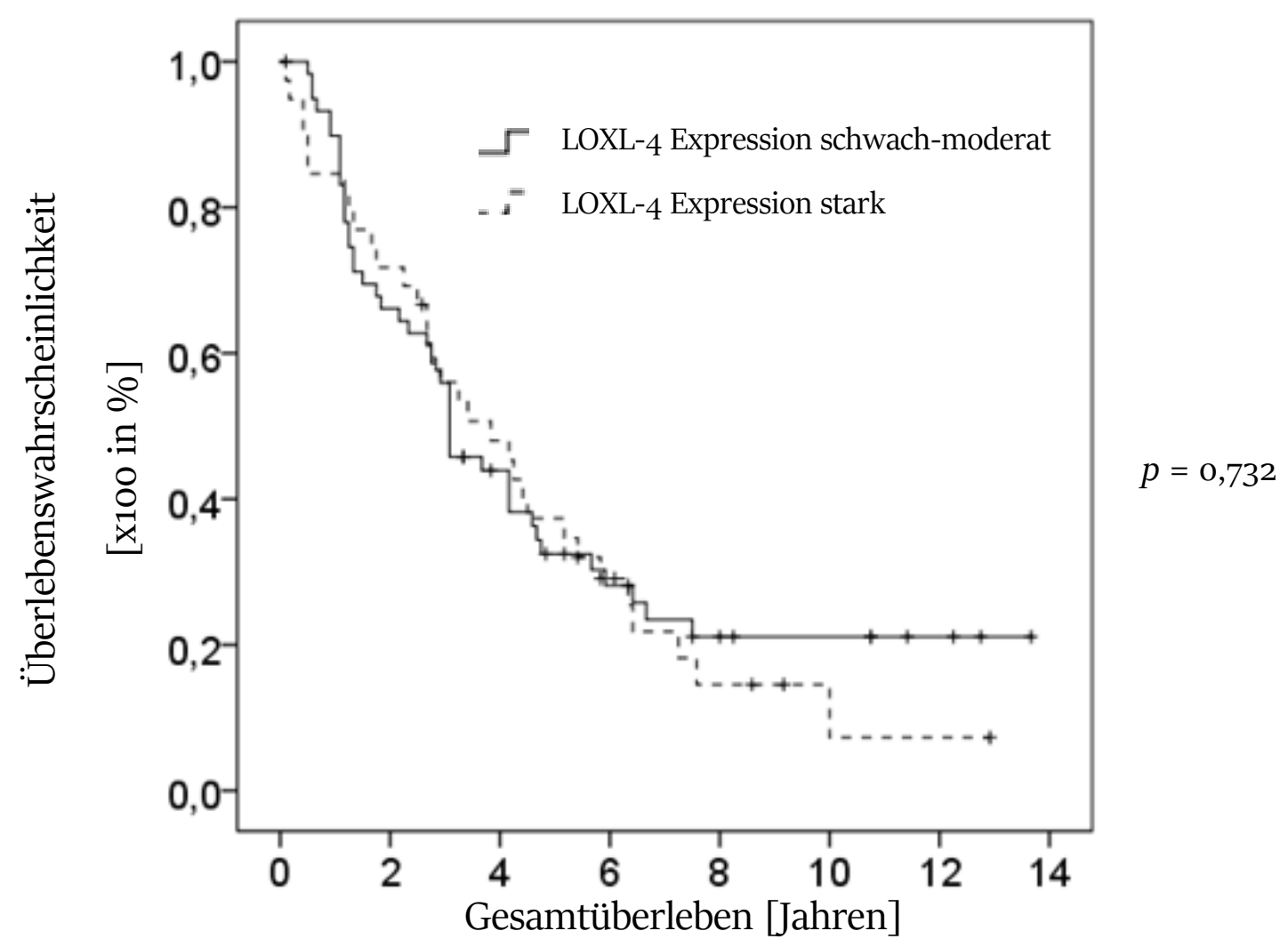

Abbildung 10: Zeitverlauf von Überlebenskurven in Abhängigkeit von verschiedenen LOXL-4 Expressionsstadien mittels der Kaplan-Meier-Methode 


\section{Diskussion}

Das Ovarialkarzinom ist durch eine ungünstige Prognose sowohl durch eine hohe Rezidivrate von über $65 \%$ als auch durch eine hohe Mortalitätsrate $(6,9 \%)$ gekennzeichnet (Bookman 2005, Caspritz et al. 2017). Dies liegt an der meist langen symptomfreien Progression und einer daraus resultierenden späten Detektion. Bei mindestens $75 \%$ der Patientinnen wird das Ovarialkarzinom in einem bereits fortgeschrittenen FIGO-Stadium (III und IV) erstmals diagnostiziert (Sehouli and Fotopoulou 2012). Auch das Fehlen eines durch Leitlinien empfohlenen Screenings macht es schwierig, das Ovarialkarzinom frühzeitig $\mathrm{zu}$ entdecken und $\mathrm{zu}$ therapieren. Aus diesem Grund nehmen Tumormarker-Tests bei den meisten karzinomatösen Erkrankungen, aber vor allem bei Ovarialkarzinomen, eine zunehmend wichtigere Rolle als aussagekräftige diagnostische Untersuchungsmöglichkeit ein. In dieser Studie liegt somit ein Schwerpunkt auf der Beurteilung der LOXL-4 Expression in Ovarialkarzinomen anhand immunhistochemischer Analysen, im Hinblick auf die Korrelationen mit klinischpathologischen Parametern. Die vermehrte LOXL-4 Expression konnte in 102 Ovarialkarzinom TMAs dargestellt werden. Für die umfangreiche und detaillierte statistische Auswertung wurde eine Datenbank mit den dazugehörigen klinischpathologischen Befunden als Grundlage verwendet. Durch die immunhistochemischen Untersuchungen mit der anschließenden statistischen Auswertung konnten Korrelationen zwischen den einzelnen klinisch-pathologischen Parametern und der LOXL-4 Expression veranschaulicht werden. $\mathrm{Zu}$ diesen Parametern zählten das Operationsalter, der Fernmetastasenstatus, das TumorGrading, die FIGO-Klassifizierung und die Rezidivrate der untersuchten Patientinnen. 


\subsection{LOXL-4 und das Ovarialkarzinom}

In vorausgegangenen Studien wurde kontrovers über die Lysyloxidase Familie mit ihren Subtypen diskutiert. Widersprüchlich waren dabei sowohl die Aussage über die Funktion und Wirkung als auch die erzielten Ergebnisse der einzelnen Studien (Erler et al. 2006). Ein Zusammenhang zwischen dem tumorsuppressiven Charakter des Lysyloxidase-Propeptid, welches eine Vorstufe des LOXL-4 Peptides darstellt, konnte sowohl bei Mamma-, als auch bei Lungen- und Prostatakarzinomen in zahlreichen Studien wissenschaftlich belegt werden (Min et al. 2007, Sanchez-Morgan et al. 2011, Bais et al. 2012, Bais et al. 2015, Ozdener et al. 2016). In hepatozellulären Karzinomen wurde zudem nicht nur die Hemmung der Zellmigration und Zellproliferation nachgewiesen, sondern auch die korrelierende Erhöhung der Apoptoserate bei erhöhter Lysyloxidase-Propetid-Expressionsrate. Diese Wirkungsweise bestätigt die tumorsuppressive Rolle des Lysyloxidase-Propetids (Zheng et al. 2014). Durch den Nachweis der Hemmung von onkogenen Signalwegen anhand der Genmethylierung und somatischen Mutationen in Blasenkarzinomen konnte ebenfalls den LOXL-Subtypen LOXL-1 und LOXL-4 ein tumorsuppressiver Charakter zugeschrieben werden ( $\mathrm{Wu}$ et al. 2007). Diese tumorsuppressiven Eigenschaften des LOXL-4 Peptides konnten zudem in Untersuchungen ebenso an Hepatozellulären-, und Triple-Negativen Mammakarzinomen bestätigt werden (Tian et al. 2015, Choi et al. 2017). Unsere Ergebnisse stehen hierzu im Widerspruch und bestätigen die aktuelle Studie von De Donato und Mitarbeiter aus dem Jahr 2017, die in einer retrospektiven Studie an invasiv wachsenden Ovarialkarzinomen die molekulare Pathogenese und die funktionelle Rolle des LOX-Enzymes als Tumorpromoter belegen konnten. Zusätzlich konnten sie veranschaulichen, dass LOX mehrere Aspekte in der metastatischen Kaskade fördert (De Donato et al. 2017). Auch weitere retrospektive Untersuchungen spiegeln diese Ergebnisse wieder und 
bestätigten auch dem LOX-Subtyp LOXL-4 die funktionelle Rolle bei der molekularen Pathogenese der invasiv wachsenden Kopf-und Halskarzinomen (Gorogh et al. 2007, Sebban et al. 2013, Yilmaz and Kumtepe 2016). Speziell für das Ovarialkarzinom wurden nach unserem Wissenstand bisher nur LOX, LOXL-2 und LOXL-4 untersucht. Alle drei LOX-Isotypen sind nachweislich an der Dysregulation des Ovarialkarzinoms beteiligt, induzieren einen malignen Phänotyp und fördern die Tumorprogression. Sebban und Mitarbeiter weisen durch die Ergebnisse ihrer Arbeit ebenfalls auf den vielversprechenden möglichen Einsatz von LOXL-4 bei Ovarialkarzinomen als prognostischen Marker hin und bestätigen somit unsere Ergebnisse (Sebban et al. 2013). Cho und Mitarbeiter gelangen nicht nur zu identischen Ergebnissen, sie prognostizieren LOXL-4 durch dessen antitumorgene Wirkung in Verbindung mit einer Chemotherapie zudem einen möglichen positiven Effekt auf die bisher sehr schlechte Prognose bei Ovarialkarzinom-Patientinnen (Cho et al. 2015). Auch die Ergebnisse der vorliegenden Arbeit unterstützen die Annahme, dass das hier untersuchte tumor-assoziierte Antigen LOXL-4 alle wichtigen Kriterien als Zielmolekül einer antikörperbasierenden Diagnostik bei Ovarialkarzinomen erfüllt.

\subsection{Diagnostische Wertigkeit der LOXL-4 Expression}

\subsubsection{Operationsalter der Patientinnen}

$\mathrm{Zu}$ den Risikoparametern des Ovarialkarzinoms zählt auch das Alter der Patientinnen. Aus diesem Grund wurde das Alter zum Operationszeitpunkt in Korrelation mit der LOXL-4 Expression untersucht, um eine diagnostische Aussage zu erzielen. Für eine genauere statistische Auswertung wurde die Patientinnenkohorte nach ihrem Alter in drei Gruppen unterteilt ( $\leq 50$ Jahre, 51-70 
Jahre und $\geq 71$ Jahre). Die kleinste Gruppe umfasste mit 15\% die Patientinnengruppe in einem Alter von $\leq 50$ Jahren und den größten Anteil mit 55\% machte die Gruppe der 51-70 Jährigen aus. In dem von uns untersuchten Kollektiv konnte keine statistische Beziehung zwischen den Altersgruppen und der LOXL-4 Expression mit dem exakten Test nach Fischer ermittelt werden $(\mathrm{p}=0,502)$. Das mediane Alter zum Operationszeitpunkt betrug bei den Patientinnen 61,69 Jahre. Damit liegt das mediane Alter der Patientinnen unter dem ermittelten Alter des Robert-KochInstitutes von 2013, welches bei 69 Jahren lag (Caspritz et al. 2017). Jedoch ist hier anzumerken, dass das Ovarialkarzinom stets Schwankungen in seiner Inzidenz aufweist. Die Erkrankungsrate hat in Deutschland ab 198o bis Mitte der 1990er Jahre zunächst zu- und dann anschließend wieder abgenommen. Somit ergibt sich zwischen 1980 und 2006 ein Anstieg der Raten um ca. 10\% und eine Steigerung der Erkrankungsfälle um 40\%, jedoch ist anzumerken, dass nach 1990 fast ausschließlich die Erkrankungsrate der über 70-jährigen Frauen anstiegen (Husemann et al. 2010).

\subsubsection{LOXL-4 und das Tumor-Grading}

Der spezielle Grad der normativen Abweichung von gesundem zu verändertem Gewebe liefert bei vielen karzinomatösen Erkrankungen Informationen über die Entartungsneigung und den aggressiven Charakter des Tumors. Somit soll in der vorliegenden Arbeit der Fragestellung nachgegangen werden, inwieweit ein Zusammenhang zwischen der LOXL-4 Expression und dem Tumor-Grading besteht. Anhand der vorliegenden Studie konnte mithilfe des Chi-Quadrat-Tests eine signifikante Korrelation nachgewiesen werden $(p=0,018)$. Im Gegensatz zu anderen gynäkologischen Karzinomen ist es bei Ovarialkarzinomen jedoch durch dessen vielfältige histologische Entartungserscheinung schwierig, ein einheitliches und 
adäquates Graduierungssystem anzuwenden. Dies ist der Grund, warum es bisherigen Systemen bei der Graduierung von Ovarialkarzinomen sowohl an Einfachheit als auch an Reproduzierbarkeit und prognostischer Bedeutung mangelt (Mayr and Diebold 2000). Bislang konnte der Nutzen eines Graduierungssystems bei Ovarialkarzinomen noch nicht nachgewiesen werden (Silverberg 2000). Immunhistochemisch konnten jedoch aufgrund ihres Entartungscharakters und der damit verbundenen LOXL-4 Reaktivität alle Ovarialkarzinomproben detektiert werden. Demzufolge könnte durch die Anwendung des LOXL-4-Antikörpers auch schon frühe Stadien des Ovarialkarzinoms erkannt und frühzeitig behandelt werden.

\subsubsection{LOXL-4 und der Fernmetastasenstatus}

Um die prognostische und diagnostische Wertigkeit von LOXL-4 zu überprüfen, wurde die Expressionsstärke des LOXL-4 Proteins in Korrelation mit dem Fernmetastasenstatus untersucht. Vorläuferstudien kamen zu dem Ergebnis, dass andere Tumoridentitäten eine Korrelation zwischen erhöhten LOXL-4 Expressionswerten und dem metastasierenden Wachstumsverhalten des Tumors aufweisen. Somit konnte eine erhöhte LOXL-4 Expression bei Mammakarzinomen (Kirschmann et al. 2002) und bei Plattenepithelkarzinomen des oberen Aerodigestivtraktes (Gorogh et al. 2008) belegt werden. Eine vorausgegangene vergleichende Studie beschäftigte sich mit dem invasiven und metastasierenden Wachstumsverhalten von Ovarialkarzinomen und deren Korrelation mit erhöhten LOX-Gen-Expressionswerten (Ji et al. 2013). Die Autoren haben eine signifikante Korrelation zwischen der vermehrten LOX-Expression und dem Metastasenstatus belegt. Mit den in der vorliegenden Arbeit erzielten Ergebnissen konnte keine statistische Signifikanz von erhöhten LOXL-4 Expressionswerten und dem 
metastasierenden Wachstumsverhalten von Ovarialkarzinomen mit dem Exakten Test nach Fischer $(\mathrm{p}=0,776)$ ermittelt werden.

\subsubsection{LOXL-4 und die FIGO-Klassifikation}

Damit die Prognose der an Ovarialkarzinom erkrankten Patientinnen zukünftig verbessert werden kann, ist die Diagnosestellung in einem möglichst frühen Stadium unabdingbar. Frühstadien (FIGO I und II) zeigen eine deutlich bessere 5-JahresÜberlebens-Prognose, als fortgeschrittene Ovarialkarzinom Stadien (FIGO III und IV) (Brun et al. 2000). Der Verlauf der Erkrankung bei einem höhergradigen Befall ist zusätzlich durch die Größe des verbleibenden Tumorrestes gekennzeichnet. In der vorliegenden Arbeit wurde, um die Fallzahl zu erhöhen, die FIGO-Klassifikation in die Gruppe der $\leq 2 \mathrm{~cm}$ großen Tumore (1a $-3 \mathrm{~b})$ und in die Gruppe der $>2 \mathrm{~cm}$ großen Tumore (3c) zusammengefasst. Zudem wurde in der statistischen Auswertung der FIGO-Klassifikation das FIGO-Stadium IV nicht mit einbezogen, da es sich um Fernmetastasen im Bereich des Peritoneums handelte, welche hierbei gesondert statistisch untersucht und ausgewertet wurden. Bei der Diagnosestellung wurden in 65,1\% der Fälle Tumore mit einer Ausdehnung von $>2 \mathrm{~cm}$ ermittelt. In 34,9\% der Fälle wies der Tumor eine Ausdehnung von $\leq 2 \mathrm{~cm}$ auf. Eine Korrelation zwischen der LOXL-4 Expression und der modifizierten FIGO-Klassifikation konnte signifikant anhand des Exakten Tests nach Fischer ermittelt werden $(\mathrm{p}=0,011)$. Somit konnte LOXL-4 als ein geeigneter Diagnosemarker verifiziert werden. 


\subsubsection{LOXL-4 und die Rezidivrate}

Trotz maximaler Primärtherapie erleiden 65-70\% der Patientinnen mit einem FIGOStadium III/IV innerhalb der ersten drei Jahre ein Rezidiv und versterben (Sehouli et al. 2008, Sehouli and Fotopoulou 2012). Hinsichtlich dieser schlechten Prognose liegt ein weiterer Fokus dieser Arbeit auf der Rezidivrate der untersuchten Ovarialkarzinomkohorte. Die Einteilung der Rezidive erfolgt in der Regel nach dem Zeitpunkt des Auftretens. Dabei wird zwischen Frührezidiven ( $<6$ Monate nach der Beendigung der platinhaltigen First-Line-Chemotherapie) und Spätrezidive ( $>6$ Monate nach der Beendigung der platinhaltigen First-Line-Chemotherapie) unterschieden (Sehouli 2011). In den in dieser Arbeit untersuchten Fällen entwickelten 69,6\% der Ovarialkarzinom-Patientinnen ein Rezidiv. Eine signifikante Korrelation zwischen der Rezidivrate und der LOXL-4 Expression ließ sich jedoch nicht nachweisen $(p=0,508)$.

\subsection{Prognostische Wertigkeit der LOXL-4 Expression}

\section{LOXL-4 Expressionstärke und das Gesamtüberleben}

Mit der Erstbeschreibung des invasiven Charakters der LOX-Familie 2002 durch Kirschmann und Mitarbeiter rückt sowohl die Lysyloxidase (LOX) als auch die Isoform LOXL-4 immer mehr ins Zentrum weiterer wissenschaftlicher Untersuchungen. $\mathrm{Zu}$ den gewonnenen Kenntnissen, dass das Enzym eine wichtige Rolle bei der Vernetzung von Kollagen oder Elastin im Extrazellularraum einnimmt, konnte dargelegt werden, dass LOX ebenfalls in die Regulation der Gentranskription, Migration und Zelladhäsion involviert ist und folglich sowohl extra- als auch intrazelluläre Vorgänge beeinflusst (Payne et al. 2007). Diese Funktionen und die 
damit einhergehende LOX-Expression scheinen besonders in karzinogen verändertem Gewebe vorhanden zu sein und machen sie bei der Suche nach möglichen diagnostischen und prognostischen Tumormarker zum Ziel der Forschung. Sebban und Mitarbeiter weisen durch die Ergebnisse ihrer Arbeit ebenfalls auf den vielversprechenden möglichen Einsatz von LOXL-4 bei Ovarialkarzinomen als prognostischen Marker hin (Sebban et al. 2013). Unsere Ergebnisse unterstützen die diagnostische Wertigkeit des LOXL-4 Proteins bei Ovarialkarzinomen. Alle Ovarialkarzinome konnten in den Proben durch eine LOXL4 Expression detektiert werden. Die prognostische Wertigkeit konnte jedoch bis dato nicht signifikant dargelegt werden. Die 3-Jahres-Überlebensrate, der in dieser Arbeit untersuchten Patientinnenkohorte lag bei ca. 55\%, die 5-Jahres-Überlebensrate lag bei ca. 34\% und die 10-Jahres-Überlebensrate lag bei ca. 18\%. Die Überlebensraten lagen somit unterhalb der vom Robert-Kochinstitutes ermittelten 5- und 10- JahresÜberlebensraten, die bei ca. 41\% und 32\% lagen (RKI 2016). Diese Abweichungen, verglichen mit den aktuellen Überlebensraten des Robert-Koch-Institutes, lassen sich sowohl mit der abweichenden Untersuchungszeit der vorliegenden Patientinnenkohorte in den Jahren zwischen 1998 bis 2011 als auch mit den seither verbesserten Therapiemöglichkeiten begründen. Bei der Auswertung der LOXL-4 Expressionsstärke und der Überlebenswahrscheinlichkeit von OvarialkarzinomPatientinnen ließ sich anhand des Log-Rank-Tests kein signifikanter Zusammenhang feststellen $(p=0,246)$. Eine mögliche Ursache könnte in den vielfältigen histologischen Erscheinungs- und Ausbreitungsformen des Ovarialkarzinoms liegen und der damit einhergehenden erschwerten Vergleichbarkeit bei der mikroskopischen Auswertung. Zudem können Abweichungen in den Ergebnissen der unterschiedlichen Studien anhand des eingesetzten LOXL-4-Antikörpers begründet sein. Die eingesetzten LOXL-4-Antikörper können auch gegen unterschiedliche 
Epitope desselben Antigens gerichtet sein. Durch die hohe Sequenzhomologie der einzelnen LOX-Isoformen ist es einem anti-LOX-Antikörper möglich, verschiedene LOX-Isoformen zu detektieren. Der in dieser Arbeit selbst hergestellte und verwendete Antikörper ist ein monoklonaler Antikörper, welcher an eine spezifische LOXL-4 Sequenz dockt und mit keiner anderen LOX-Isoform interagiert. In Bezug auf das Gesamtüberleben spiegeln, die in dieser Arbeit gewonnenen Ergebnisse den aktuellen Stand wider, dass die LOXL-4 Expression keine Auswirkung auf das Gesamtüberleben der Patientinnen aufweist $(\mathrm{p}=\mathrm{o}, 671)$. Dieses Ergebnis unterstützt auch die Untersuchungen anderer Tumormarker für das Ovarialkarzinom, wodurch es folglich keine Empfehlung in der aktuellen Leitlinie für eine Tumormarkerbestimmung (Leitlinienprogramm 2016) gibt. Die fehlende statistische Korrelation zwischen der Tumormarkerbestimmung und der Auswirkung auf das Gesamtüberleben der Patientinnen könnte in der Komplexität der unterschiedlichen Erscheinungs- und Ausbreitungsformen des Ovarialkarzinoms begründet sein. Des Weiteren könnte die fehlende statistische Korrelation zwischen LOXL-4 und dem Gesamtüberleben durch den Parameter der Komorbidität, der im fortgeschrittenen Alter der erkrankten Frauen vorliegt, beeinflusst werden. 


\section{Zusammenfassung}

Das Ovarialkarzinom nimmt aufgrund seiner schlechten Prognose die erste Stelle in der relativen Mortalitätsstatistik aller gynäkologischen Malignome ein. Infolgedessen nehmen Tumormarker-Tests bei dieser Erkrankung eine zunehmend wichtigere Rolle ein, um eine aussagekräftige diagnostische und prognostische Untersuchungsmöglichkeit der Patientinnen sicher zu stellen. Aus diesem Grund liegt der Schwerpunkt der vorliegenden Studie auf dem immunhistochemischen Nachweis der LOXL-4 Expression bei Ovarialkarzinomen, sowie der Prüfung ihrer Wertigkeit als diagnostisches Tool. Für die immunhistochemische Analyse wurden histopathologisch gesicherte Ovarialkarzinome untersucht, mit deren klinischpathologischen Daten vergleichend analysiert und mittels Chi-Quadrat-Test, Likelihood-Quotient, Log-Rank-Test sowie der Kaplan-Meier-Methode und dem Exakten Test nach Fisher statistisch ausgewertet. Insgesamt wiesen alle der 102 primären Ovarialkarzinome eine LOXL-4 Expression in unterschiedlicher Ausprägung auf. Des Weiteren konnte ein signifikanter Zusammenhang zwischen der LOXL-4 Expressionsstärke und Tumor-Grading ( $\mathrm{p}=0.018)$, sowie FIGOKlassifizierung $(\mathrm{p}=0.011)$ validiert werden. Es konnte keine signifikante Korrelation zwischen der LOXL-4 Expression und dem Patientinnenalter bei Erstoperation, sowie dem Fernmetastasenstatus und der Rezidivrate ermittelt werden. Im Hinblick auf die LOXL-4 Expressionsstärke und der Überlebenswahrscheinlichkeit ließ sich statistisch kein signifikanter Zusammenhang feststellen. Insgesamt betrachtet, deuten die in dieser Arbeit erzielten Ergebnisse darauf hin, dass das tumor-assoziierte Antigen LOXL-4 alle wichtigen Kriterien als Tumormarker für das Ovarialkarzinom erfüllt. Somit könnte der immunhistochemische Nachweis von LOXL-4 als geeignetes Instrument in der Früherkennung eingesetzt werden und helfen, die Prognose der Patientinnen durch eine frühzeitigere Diagnose und Therapie zu verbessern. 


\section{Literaturverzeichnis:}

Antoniou, A., P. D. Pharoah, S. Narod, H. A. Risch, J. E. Eyfjord, J. L. Hopper, N. Loman, H. Olsson, O. Johannsson, A. Borg, B. Pasini, P. Radice, et al. (2003). "Average risks of breast and ovarian cancer associated with BRCA1 or BRCA2 mutations detected in case Series unselected for family history: a combined analysis of 22 studies." Am J Hum Genet 72(5): 1117-1130.

Asuncion, L., B. Fogelgren, K. S. Fong, S. F. Fong, Y. Kim, K. Csiszar (2001). "A novel human lysyl oxidase-like gene (LOXL4) on chromosome 10q24 has an altered scavenger receptor cysteine rich domain." Matrix Biol 20(7): 487-491.

Bais, M. V., M. A. Nugent, D. N. Stephens, S. S. Sume, K. H. Kirsch, G. E. Sonenshein, P. C. Trackman (2012). "Recombinant lysyl oxidase propeptide protein inhibits growth and promotes apoptosis of preexisting murine breast cancer xenografts." PLoS One 7(2): e31188.

Bais, M. V., G. B. Ozdener, G. E. Sonenshein, P. C. Trackman (2015). "Effects of tumor-suppressor lysyl oxidase propeptide on prostate cancer xenograft growth and its direct interactions with DNA repair pathways." Oncogene 34(15): 1928-1937.

Bonadona, V., B. Bonaiti, S. Olschwang, S. Grandjouan, L. Huiart, M. Longy, R. Guimbaud, B. Buecher, Y. J. Bignon, O. Caron, C. Colas, C. Nogues, et al. (2011). "Cancer risks associated with germline mutations in MLH1, MSH2, and MSH6 genes in Lynch syndrome." JAMA 305(22): 2304-2310. 
Bookman, M. A. (2005). "Standard treatment in advanced ovarian cancer in 2005: the state of the art." Int J Gynecol Cancer 15 Suppl 3: $212-220$.

Brown, R. W., R. Chirala (1995). "Utility of microwave-citrate antigen retrieval in diagnostic immunohistochemistry." Mod Pathol 8(5): 515520 .

Bruhn, H., R. Junker, H. Schäfer, S. Schreiber (2011). Labor Medizin. 3.0.Schattauer GmbH. Stuttgart.

Brun, J. L., A. Feyler, G. Chene, J. Saurel, G. Brun, C. Hocke (2000). "Long-term results and prognostic factors in patients with epithelial ovarian cancer." Gynecol Oncol 78(1): 21-27.

Bundesamt, S. (2015). "Die 10 häufigsten Todesfälle durch Krebs." from

https://www.destatis.de/DE/ZahlenFakten/GesellschaftStaat/Gesundh eit/Todesursachen/Tabellen/Sterbefaelle KrebsInsgesamt.html.

Burges, A., B. Schmalfeldt (2011). "Ovarian cancer: diagnosis and treatment." Dtsch Arztebl Int 108(38): 635-641.

Caspritz, S., M. Christ, A. Ernst, J. Folkerts, J. Hansmann, S. Klein, K. Kranzhöfer, B. Kunz, K. Manegold, A. Penzkofer, K. Treml, S. Weg-Remers, et al. (2017). Krebs in Deutschland für 2013/2014. 11. Ausgabe, 88-91, Robert Koch-Institut (Hrsg) und die Gesellschaft der epidemiologischen Krebsregister in Deutschland e.V. (Hrsg), Berlin. 
Chen, X., J. Zhang, W. Cheng, D. Y. Chang, J. Huang, X. Wang, L. Jia, D. G. Rosen, W. Zhang, D. Yang, D. M. Gershenson, A. K. Sood, et al. (2013). "CA-125 level as a prognostic indicator in type I and type II epithelial ovarian cancer." Int J Gynecol Cancer 23(5): 815822.

Chen, Y. L., M. C. Chang, C. A. Chen, H. W. Lin, W. F. Cheng, C. L. Chien (2012). "Depletion of regulatory $\mathrm{T}$ lymphocytes reverses the imbalance between pro- and anti-tumor immunities via enhancing antigen-specific T cell immune responses." PLoS One 7(10): e47190.

Cho, A., V. M. Howell, E. K. Colvin (2015). "The Extracellular Matrix in Epithelial Ovarian Cancer - A Piece of a Puzzle." Front Oncol 5: 245.

Choi, S. K., H. S. Kim, T. Jin, W. K. Moon (2017). "LOXL4 knockdown enhances tumor growth and lung metastasis through collagendependent extracellular matrix changes in triple-negative breast cancer." Oncotarget 8: 11977-11989.

Csiszar, K. (2001). "Lysyl oxidases: a novel multifunctional amine oxidase family." Prog Nucleic Acid Res Mol Biol 70: 1-32.

De Donato, M., M. Petrillo, E. Martinelli, F. Filippetti, G. F. Zannoni, G. Scambia, D. Gallo (2017). "Uncovering the role of nuclear Lysyl oxidase (LOX) in advanced high grade serous ovarian cancer." Gynecol Oncol 146(1): 170-178. 
Deng, H., L. Lv, Y. Li, C. Zhang, F. Meng, Y. Pu, J. Xiao, L. Qian, W. Zhao, Q. Liu, D. Zhang, Y. Wang, et al. (2014). "miR-193a-3p regulates the multi-drug resistance of bladder cancer by targeting the LOXL4 gene and the Oxidative Stress pathway." Mol Cancer 13: 234.

Diercks, I., T. Görögh (2015). "Immunohistochemical analysis of clinical and pathological relevance of LOXL4- and survivin expressions in oropharyngeal carcinomas." Oral Oncol Volume 51(5): e49.

Erler, J. T., K. L. Bennewith, M. Nicolau, N. Dornhofer, C. Kong, Q. T. Le, J. T. Chi, S. S. Jeffrey, A. J. Giaccia (2006). "Lysyl oxidase is essential for hypoxia-induced metastasis." Nature 440(7088): 12221226.

Fathalla, M. F. (1972). "Factors in the causation and incidence of ovarian cancer." Obstet Gynecol Surv 27(11): 751-768.

Feige, A., A. Rempen, W. Würfel, J. Jawny, A. Rohde (2005). Frauenheilkunde: Fortpflanzungsmedizin Geburtsmedizin Onkologie Psychosomatik. 3. Auflage.Urban\&Fischer Verlag. München.

Gätje, R., C. Eberle, C. Scholz, M. Lübke, C. Solbach, K. Muschel, S. Kissler, F. Siedentopf, T. Weißenbacher, G. Debus, I. Schuhmacher, K. Lato, et al. (2015). Kurzlehrbuch Gynäkologie und Geburtshilfe. 2.0.Thieme Verlag. Stuttgart. 
Gorogh, T., C. Holtmeier, J. B. Weise, M. Hoffmann, P. Ambrosch, M. Laudien, K. Csiszar (2008). "Functional analysis of the 5' flanking domain of the LOXL4 gene in head and neck squamous cell carcinoma cells." Int J Oncol 33(5): 1091-1098.

Gorogh, T., J. B. Weise, C. Holtmeier, P. Rudolph, J. Hedderich, S. Gottschlich, M. Hoffmann, P. Ambrosch, K. Csiszar (2007). "Selective upregulation and amplification of the lysyl oxidase like-4 (LOXL4) gene in head and neck squamous cell carcinoma." J Pathol 212(1): 7482.

Holtmeier, C., T. Gorogh, U. Beier, J. Meyer, M. Hoffmann, S. Gottschlich, K. Heidorn, P. Ambrosch, S. Maune (2003). "Overexpression of a novel lysyl oxidase-like gene in human head and neck squamous cell carcinomas." Anticancer Res 23(3B): 2585-2591.

Hsu, S. M., L. Raine, H. Fanger (1981). "The use of antiavidin antibody and avidin-biotin-peroxidase complex in immunoperoxidase technics." Am J Clin Pathol 75(6): 816-821.

Husemann, U., P. Kaatsch, A. Katalinic, B. Bertz, J. Haberland, K. Kraywinkel, W. Wolf (2010). Krebs in Deutschland 2005/2006. Häufigkeiten und Trends, 68-71, Robert Koch-Institut (Hrsg.) und die Gesellschaft der epidemiologischen Krebsregister in Deutschland e.V. (Hrsg.), Berlin.

Ji, F., Y. Wang, L. Qiu, S. Li, J. Zhu, Z. Liang, Y. Wan, W. Di (2013). "Hypoxia inducible factor 1alpha-mediated LOX expression correlates with migration and invasion in epithelial ovarian cancer." Int $\mathrm{J}$ Oncol 42(5): 1578-1588. 
Kang, S. (2011). "The role of neoadjuvant chemotherapy in ovarian cancer patients with extensive tumor burden." J Gynecol Oncol 22(4): 299-300.

Kim, H. S., N. H. Park, H. H. Chung, J. W. Kim, Y. S. Song, S. B. Kang (2008). "Serum CA-125 level after 6 cycles of primary adjuvant chemotherapy is a useful prognostic factor for complete responders' survival in patients with advanced epithelial ovarian cancer." Onkologie 31(6): 315-320.

Kinde, I., C. Bettegowda, Y. Wang, J. Wu, N. Agrawal, M. Shih Ie, R. Kurman, F. Dao, D. A. Levine, R. Giuntoli, R. Roden, J. R. Eshleman, et al. (2013). "Evaluation of DNA from the Papanicolaou test to detect ovarian and endometrial cancers." Sci Transl Med 5(167): 167ra164.

Kirschmann, D. A., E. A. Seftor, S. F. Fong, D. R. Nieva, C. M. Sullivan, E. M. Edwards, P. Sommer, K. Csiszar, M. J. Hendrix (2002). "A molecular role for lysyl oxidase in breast cancer invasion." Cancer Res 62(15): 4478-4483.

Landen, C. N., Jr., M. J. Birrer, A. K. Sood (2008). "Early events in the pathogenesis of epithelial ovarian cancer." J Clin Oncol 26(6): 995-1005.

Leitlinienprogramm (2016, Oktober 2016). "S3-Leitlinie Diagnostik, Therapie und Nachsorge maligner Ovarialtumore." Kurzversion 2.0. from https://www.ago-online.de/fileadmin/downloads/leitlinien/ovar/ 2016/032-035-OLk_Ovarialkarzinom_2016-10.pdf. 
Lenhard, M., P. Stieber, L. Hertlein, A. Kirschenhofer, S. Furst, D. Mayr, D. Nagel, K. Hofmann, K. Krocker, A. Burges (2011). "The diagnostic accuracy of two human epididymis protein 4 (HE4) testing systems in combination with CA125 in the differential diagnosis of ovarian masses." Clin Chem Lab Med 49(12): 2081-2088.

Li, R. K., W. Y. Zhao, F. Fang, C. Zhuang, X. X. Zhang, X. M. Yang, S. H. Jiang, F. Z. Kong, L. Tu, W. M. Zhang, S. L. Yang, H. Cao, et al. (2015). "Lysyl oxidase-like 4 (LOXL4) promotes proliferation and metastasis of gastric cancer via FAK/Src pathway." J Cancer Res Clin Oncol 141(2): 269-281.

Mayr, D., J. Diebold (2000). "Grading of ovarian carcinomas." Int J Gynecol Pathol 19(4): 348-353.

Min, C., K. H. Kirsch, Y. Zhao, S. Jeay, A. H. Palamakumbura, P. C. Trackman, G. E. Sonenshein (2007). "The tumor suppressor activity of the lysyl oxidase propeptide reverses the invasive phenotype of Her-2/neu-driven breast cancer." Cancer Res 67(3): 1105-1112.

Modugno, F., R. B. Ness, G. O. Allen, J. M. Schildkraut, F. G. Davis, M. T. Goodman (2004). "Oral contraceptive use, reproductive history, and risk of epithelial ovarian cancer in women with and without endometriosis." Am J Obstet Gynecol 191(3): 733-740.

Molina, R., J. M. Escudero, J. M. Auge, X. Filella, L. Foj, A. Torne, J. Lejarcegui, J. Pahisa (2011). "HE4 a novel tumour marker for ovarian cancer: comparison with CA 125 and ROMA algorithm in patients with gynaecological diseases." Tumour Biol 32(6): 1087-1095. 
Molnar, J., K. S. Fong, Q. P. He, K. Hayashi, Y. Kim, S. F. Fong, B. Fogelgren, K. M. Szauter, M. Mink, K. Csiszar (2003). "Structural and functional diversity of lysyl oxidase and the LOX-like proteins." Biochim Biophys Acta 1647(1-2): 220-224.

Moon, J. H., H. J. Lee, W. D. Kang, C. H. Kim, H. S. Choi, S. M. Kim (2013). "Prognostic value of serum CA-125 in patients with advanced epithelial ovarian cancer followed by complete remission after adjuvant chemotherapy." Obstet Gynecol Sci 56(1): 29-35.

Ozdener, G. B., M. V. Bais, P. C. Trackman (2016). "Determination of cell uptake pathways for tumor inhibitor lysyl oxidase propeptide." Mol Oncol 10(1): 1-23.

Payne, S. L., M. J. Hendrix, D. A. Kirschmann (2007). "Paradoxical roles for lysyl oxidases in cancer--a prospect." J Cell Biochem 101(6): 1338-1354.

Post, P. N., M. K. Casparie, J. L. Blaauwgeers, S. de Blok (2005). "Reduced risk of ovarian cancer after hysterectomy." Acta Obstet Gynecol Scand 84(10): 1024; author reply 1024-1025.

Rebbeck, T. R., H. T. Lynch, S. L. Neuhausen, S. A. Narod, L. Van't Veer, J. E. Garber, G. Evans, C. Isaacs, M. B. Daly, E. Matloff, O. I. Olopade, B. L. Weber, et al. (2002). "Prophylactic oophorectomy in carriers of BRCA1 or BRCA2 mutations." N Engl J Med 346(21): 1616-1622. 
Riman, T., P. W. Dickman, S. Nilsson, N. Correia, H. Nordlinder, C. M. Magnusson, I. R. Persson (2002). "Risk factors for invasive epithelial ovarian cancer: results from a Swedish case-control study." Am J Epidemiol 156(4): 363-373.

RKI (2016). Bericht zum Krebsgeschehen in Deutschland 2016.Rucksaldruck GmbH \& Co KG. Berlin.

Roffeis, J. (2011). Untersuchungen zur strukturellen Basis der Positionsspezifität der humanen 15-Lipoxygenase-2 sowie zur Expression des Enzyms beim Ovarialkarzinom. Medizinische Fakultät Charité. Universitätsmedizin Berlin, Freie Universität Berlin

Rustin, G. J., M. E. van der Burg, C. L. Griffin, D. Guthrie, A. Lamont, G. C. Jayson, G. Kristensen, C. Mediola, C. Coens, W. Qian, M. K. Parmar, A. M. Swart, et al. (2010). "Early versus delayed treatment of relapsed ovarian cancer (MRC OV05/EORTC 55955): a randomised trial." Lancet 376(9747): 1155-1163.

Sanchez-Morgan, N., K. H. Kirsch, P. C. Trackman, G. E. Sonenshein (2011). "The lysyl oxidase propeptide interacts with the receptor-type protein tyrosine phosphatase kappa and inhibits beta-catenin transcriptional activity in lung cancer cells." Mol Cell Biol 31(16): 3286-3297.

Sarojini, S., A. Tamir, H. Lim, S. Li, S. Zhang, A. Goy, A. Pecora, K. S. Suh (2012). "Early detection biomarkers for ovarian cancer." J Oncol 2012: 709049. 
Sebban, S., R. Golan-Gerstl, R. Karni, O. Vaksman, B. Davidson, R. Reich (2013). "Alternatively spliced lysyl oxidase-like 4 isoforms have a pro-metastatic role in cancer." Clin Exp Metastasis 30(1): 103-117.

Sehouli, J. (2011). "Ovarialkarzinom." Gynakol Geburtsmed Gynakol Endokrinol 7: 84-95.

Sehouli, J., C. Fotopoulou (2012). Multimodales Management des Ovarialkarzinoms. 2.Uni-med Verlag AG. Bremen.

Sehouli, J., C. Fotopoulou, G. Oskay-Özcelik, D. Koensgen-Mustea, A. Mustea, U. Neumann, H. Weidemann, P. Neuhaus, W. Lichtenegger (2008). Operative Therapie beim Ovarialkarzinomrezidiv. Stellenwert und praktische Aspekte. Der Onkologe, Springer Medizin Verlag

Silverberg, S. G. (2000). "Histopathologic grading of ovarian carcinoma: a review and proposal." Int J Gynecol Pathol 19(1): 7-15.

Steinke, V., C. Engel, R. Buttner, H. K. Schackert, W. H. Schmiegel, P. Propping (2013). "Hereditary nonpolyposis colorectal cancer (HNPCC)/Lynch syndrome." Dtsch Arztebl Int 110(3): 32-38.

Tian, M., W. Liu, L. Jin, X. Jiang, L. Yang, Z. Ding, Y. Shen, Y. Peng, D. Gao, L. Li, J. Zhou, S. Qiu, et al. (2015). "LOXL4 is downregulated in hepatocellular carcinoma with a favorable prognosis." Int J Clin Exp Pathol 8(4): 3892-3900. 
Weise, J. B., P. Rudolph, A. Heiser, M. L. Kruse, J. Hedderich, C. Cordes, M. Hoffmann, O. Brant, P. Ambrosch, K. Csiszar, T. Gorogh (2008). "LOXL4 is a selectively expressed candidate diagnostic antigen in head and neck cancer." Eur J Cancer 44(9): 1323-1331.

Wu, G., Z. Guo, X. Chang, M. S. Kim, J. K. Nagpal, J. Liu, J. M. Maki, K. I. Kivirikko, S. P. Ethier, B. Trink, D. Sidransky (2007). "LOXL1 and LOXL4 are epigenetically silenced and can inhibit ras/extracellular signal-regulated kinase signaling pathway in human bladder cancer." Cancer Res 67(9): 4123-4129.

Yilmaz, E. P., Y. Kumtepe (2016). "Endometrial and Ovarian Cancer with MR Imaging Importance of Serum HE4 and CA 125 Levels in the Extent of Disease at Evaluation." Eurasian J Med 48(3): 192-198.

Zheng, Y., X. Wang, H. Wang, W. Yan, Q. Zhang, X. Chang (2014). "Expression of the lysyl oxidase propeptide in hepatocellular carcinoma and its clinical relevance." Oncol Rep 31(4): 1669-1676. 


\section{Danksagung}

Zu dem Gelingen dieser Doktorarbeit haben verschiedene Personen mit Engagement und Unterstützung beigetragen und sollen daher keinesfalls unerwähnt bleiben: Frau Prof. med. Petra Ambrosch, für die Möglichkeit und Unterstützung diese Arbeit in ihrer Abteilung der „Experimentellen Onkologie“ anfertigen zu können.

Einen besonders großen Dank gilt meinem Doktorvater Priv.-Do. Dr. rer. nat. Tibor Görögh. Ich hätte mir keinen besseren Doktorvater wünschen können.

Zudem möchte ich Frau Dr. Elgar Susanne Quabius für ihre hervorragende Unterstützung an so manch schwierigen Punkten danken. Sie hat maßgeblich zu dem Gelingen dieser Arbeit beigetragen.

Des Weiteren möchte ich Herrn Hans-Peter Küchenmeister für seine jahrelange Förderung und Unterstützung danken.

Meiner Schwester Verena Loba möchte ich für ihre liebevolle Unterstützung und Korrekturbereitschaft bei dieser Arbeit danken.

Mein besonderer Dank gilt auch meinen Eltern Silke und Gerd Serke, sowie meinem Partner Christian Kademann und meiner Schwiegermutter Dr. Ute Kademann, die mich bei all meinen Arbeiten und Projekten ausnahmslos unterstützten.

Ebenso herzlich möchte ich Herrn Dr. Arthur Friedrich danken, der mir stets ein Mentor war und immer ein Teil meines Lebens bleiben wird.

Und zu guter Letzt danke ich all den Patientinnen, die durch ihre Einwilligung in die Forschung die Voraussetzungen geschaffen haben, das Ovarialkarzinom noch etwas besser zu verstehen. Ihr Schicksal verpflichtet, die Forschung weiter voranzutreiben. 


\section{Veröffentlichungen}

\section{Kongress-Abstracts und Posterpräsentationen:}

Serke V., Quabius ES., Kademann C., Alkatout I., Jüngling N., van Mackelenbergh M., Klapper W., Görögh T. (2016)

Immunhistochemische Analyse der LOXL-4 Expression und ihre klinischpathologische Relevanz bei Ovarialkarzinomen

61. Kongress der Deutschen Gesellschaft für Gynäkologie und Geburtshilfe vom 19. bis 22. Oktober 2016 in Stuttgart

Poster 76 - P106

https://www.thieme-connect.com/products/ejournals/abstract/10.1055/s0036-1592715

Kademann C, Quabius ES, Serke V, Alkatout I, Wenners A, Klapper W, Bauer M, Arnold N, Görögh T (2016)

LOXL4-Antigen-Expression und ihre klinisch-pathologische Bedeutung bei Mammakarzinomen: eine immunhistochemische Analyse

61. Kongress der Deutschen Gesellschaft für Gynäkologie und Geburtshilfe vom 19. bis 22. Oktober 2016 in Stuttgart

Poster 76 - Poo6

https://www.thieme-connect.com/products/ejournals/abstract/10.1055/s$\underline{0036-1592666}$ 